\title{
A practical approach for self-potential data acquisition, processing, and visualization
}

\author{
Stéphanie Barde-Cabusson ${ }^{1}$, Anthony Finizola ${ }^{2}$, and Niels Grobbe ${ }^{3}$
}

\begin{abstract}
We have developed a comprehensive methodology for the acquisition and processing of self-potential (SP) data, as well as some keys for the interpretation of the results. The wide applicability of the SP method and its low cost make it a popular method to use in a variety of natural environments. Despite its versatility and the fact that various published journal papers describe the method and its applications, we believe that there is an important need for a dedicated, peer-reviewed SP acquisition, processing, and visualization/interpretation paper in the scientific literature. We have identified great interest from the scientific community for such a journal paper as a guide for existing and new practitioners with their SP survey design, data acquisition, robust processing, and initial interpretation steps. We have developed a step-by-step methodology for SP data acquisition and processing, combined with practical guidance for the interpretation of collected and processed SP data, including an evaluation of common errors and typical sources of uncertainty. Our examples are based on studies in volcanic environments (e.g., hydrothermal systems); however, the processing steps and methodology are fully applicable and transferable across disciplines to SP data acquired in any environment, and for a wide variety of applications. We evaluated the field acquisition method and the low-cost equipment, the reference and closure corrections, their meaning for the SP signal, and their effect on the data set. The benefits of interpolating SP data in two steps are examined. Combining map visualization, SP versus distance, and SP versus elevation graphs appears to be a highly effective strategy to interpret the signal in terms of hydrogeologic and hydrothermal domains and to highlight structural limits in volcanic contexts as well as in other environments.
\end{abstract}

\section{Introduction}

The self-potential (SP) method is a passive geoelectrical method that is sensitive to underground fluid flows such as hydrogeologic and hydrothermal circulations. It is convenient to apply in the field, and the data are relatively easy to process. Contrary to most other geophysical methods, for the SP method, no official manual is typically delivered with the equipment. Some geophysical equipment companies have started to list SP among the methods for which they offer devices. However, this is relatively recent (less than 5 years) and the products are mainly electrodes and wires originally sold for electric resistivity or magnetotelluric surveys, which need to be combined in a customized fashion for SP acquisition purposes by the user. In other words, there is no off-the-shelf SP acquisition system available, to our knowledge. Training for the SP method is often taught by word of mouth and field experience, and equipment has to be fabricated in house or gathered from various suppliers. However, this lack of standardization also offers the benefit of flexibility: There is total freedom to adapt, for example, the choice of devices, data acquisition strategy, and data processing to the needs of each user, study setting, and target. Historically, the SP method has been used in economic mineral exploration. Now, it also expands to environmental geophysics and other applications, in which for the above described reasons it remains "the ugly duckling" that can transform into a swan (Nyquist and Corry, 2002) if proper attention is dedicated to it.

\footnotetext{
${ }^{1}$ University of Hawai'i at Mānoa, Hawai'i Institute of Geophysics and Planetology, School of Ocean and Earth Science and Technology, Honolulu, Hawaii 96822 2217, USA. E mail: sbarde@hawaii.edu (corresponding author).

${ }^{2}$ Université de La Réunion, Laboratoire GéoSciences Réunion, F 97744 Saint Denis, France and Université de Paris, Institut de Physique du Globe de Paris, CNRS, F 75005 Paris, France. E mail: finizola@ipgp.fr.

${ }^{3}$ University of Hawai'i at Mānoa, Hawai'i Institute of Geophysics and Planetology, School of Ocean and Earth Science and Technology, Honolulu, Hawaii 96822 2217, USA and University of Hawai'i at Mānoa, Water Resources Research Center, Honolulu, Hawaii 96822 2217, USA. E mail: ngrobbe@hawaii.edu.
} 


\section{Historical evolution of SP applications}

As Sheriff (1978) writes, "Electrical exploration is not used a great deal in the United States, although the French and the Soviets use it extensively." This was at the beginning of the expansion of the method, when some fundamentals of the SP theory and application were starting to be published in more detail (e.g., Semenov, 1980). Finizola (2017) describes the history of the SP method, showing that the SP method was initially used for prospecting in mining, using rudimentary equipment (Fox, 1830). It consisted of metal copper plates used as electrodes and a galvanometer measuring the electrical current between them. Nowadays, with more modern devices, SP is still a common, useful tool for ore deposit detection (see Sato and Mooney [1960] for the theory of the electrochemical mechanism and, e.g., Eppelbaum, 2019). As more experience was gained with the method, SP became a useful tool for geothermal studies, primarily in the United States (e.g., Zohdy et al., 1973; Corwin, 1976; Anderson and Johnson, 1979; Corwin and Hoover, 1979) but in the same period, this cheap and user-friendly method raised interest for applications on active volcanoes in the United States (Zablocki, 1976), and shortly thereafter in Europe (e.g., Van Ngoc et al., 1980; Ballestracci, 1982; Lénat et al., 1982; Soudoplatoff et al., 1982; Halbwachs, 1983; Lénat, 1987). As for most of the existing geophysical methods, the SP results are sometimes difficult to interpret as a stand-alone data set. Nowadays, despite these challenges, the SP method is successfully used in many studies covering a wide variety of domains such as mineral exploration (e.g., Biswas, 2017), geothermal activity and resources (e.g., Zohdy et al., 1973; Corwin, 1976; Anderson and Johnson, 1979; Corwin and Hoover, 1979; Revil and Pezard, 1998; Ishido et al., 2010; Bolós et al., 2019), hydrology, hydrogeology, and hydrogeophysics (e.g., Aubert and Atangana, 1996; Doussan et al., 2002; Revil et al., 2005; Suski et al., 2006; Jardani et al., 2009; Jouniaux et al., 2009), studies of sinkholes (e.g., Jardani et al., 2006), caves, conduits, and faults (Saribudak and Hauwert, 2017; Saribudak, 2019), dam leakage detection (Gex, 1980; Bolève et al., 2011), subglacial flows (Kulessa et al., 2003), dormant monogenetic volcanic fields (e.g., Bolós et al., 2012; Barde-Cabusson et al., 2014), and active volcanoes in general (e.g., Zablocki, 1976; Van Ngoc et al., 1980; Lénat, 1987; Finizola et al., 2002, 2003, 2004, 2009, 2017; Ishido, 2004; Hase et al., 2005; Aizawa, 2008; Revil et al., 2008, 2011; Barde-Cabusson et al., 2009, 2012; Bennati et al., 2011; Brothelande et al., 2014; Gonzales et al., 2014; Villasante-Marcos et al., 2014; Chaput et al., 2019; Grobbe and Barde-Cabusson, 2019; just to mention a few).

More specifically speaking about the processing of SP data, reference and loop/closure corrections have not always been applied to the raw data. In the 1940s, few authors mentioned the SP signal variability, in the electrical logging of oil wells (Dickey, 1944; Mounce and Rust, 1945) and associated with the mineralization context (Rao, 1943; Dessau, 1950), but this did not lead to consideration of the SP drift to be corrected before generating SP maps. The first SP maps have been performed related to mining and ore body context (Kruger and Lacy, 1949; Dessau, 1950; Gay, 1967; Henriet, 1971), but without applying the loop correction. In the early 1970s, SP prospection started in geothermal exploration (Banwell, 1970; Anderson and Johnson, 1973; Zohdy et al., 1973; Corwin, 1975), and important book chapters and an entire Ph.D. thesis were dedicated to the SP method (Corwin, 1973; Parasnis, 1973; Gex, 1977). However, it is in 1976 that the concept of closure offset and loop correction appeared for the first time. This new data processing, preliminary to elaborating an SP map was specified in a geothermal exploration in Long Valley, California (Anderson and Johnson, 1976), and also in the first SP publication applied in volcanology, on Kilauea in Hawaii (Zablocki, 1976). Since this period, the concept of SP loop correction has been adopted in various fields (volcanology, hydrogeology, etc.), but it was only mentioned by one or a few sentences in the data processing sections of the publications (Ballestracci, 1982; Schiavone and Quarto, 1984; Fournier, 1989). The most extended explanation about the loop correction is concentrated in one short paragraph (see Zablocki, 1976, p. 1302).

\section{Instrumentation developments}

Because the initial copper plate electrodes were used in early mining studies, the devices used for SP measurements evolved significantly. The first use of nonpolarizable electrodes was proposed by Barus (1882). With the developments in the field of geothermal studies, nonpolarizable electrodes were improved and were systematically used in SP acquisition, replacing the metal electrodes (Gex, 1977). Indeed, the metal electrodes were shown to generate parasitic currents through redox reactions occurring between the metal and the ground, which induces significant errors on the measurements. "Porous pot"-type copper-coppersulphate nonpolarizable electrodes were the first type used and were subsequently improved in Europe (Gex, 1977). Other types of electrodes were tested and used for prospecting and/or monitoring (Perrier et al., 1997), such as the Petiau lead-lead chloride electrodes (Petiau, 2000), which are considered to be more stable in time, and they are usually recommended for monitoring purposes. The high-impedance multimeters typically used for SP measurements need to have a 10-100 M $\Omega$ impedance, a basic accuracy of $\pm 0.09 \%$, and a DC voltage in the range of $0.1 \mathrm{mV}$ to 1000 voltage direct current. They can be further augmented with a filter for unwanted 50 $60 \mathrm{~Hz}$ signals usually present in inhabited areas. These filters are often required to avoid the effect of electric lines disrupting the SP signal. Indeed, the SP method suffers from a series of limitations associated with environmental factors; for example, poor coupling of the electrodes with the ground, the presence of tree roots, or the biological activity of ants around the electrodes all 
can disrupt the signal. Furthermore, small-scale heterogeneities of the ground can induce significant differences in the measured SP values when moving the electrode position around by a few centimeters (Boudoire et al., 2018). It is important to be aware of the instrumentation limitations and potential sources of uncertainty in the SP data, such that one can do their very best during data acquisition to minimize these influences (e.g., ensure good coupling with the ground). Furthermore, with each evolution of the devices used for SP measurements, and because the method has gained attention from professionals in a variety of fields, these limitations have become increasingly better addressable.

Despite the abundant literature on the SP method in applied geophysics and a growing knowledge of the theory behind SP signal generation (e.g., Revil and Jardani, 2013), unfortunately, some significant mistakes have occurred in the past while acquiring and/or processing SP data, such as not using closed and interconnected measurements or not correcting the data for the drift before generating SP maps.

We, and other geophysicists, have been refining the whole process until we reached an fast and efficient way to acquire and process SP data. The number of inquiries that we received concerning SP data acquisition and processing was large, such that we realized the lack of or inaccessibility of comprehensive literature regarding SP data acquisition and processing and, most importantly, the demand from the scientific community for such literature. This paper aims to reply to this demand by describing the steps from data acquisition, via processing and data correction steps, to the final visualization of SP results, as well as some important keys for their interpretation. Our experience with the method was mostly obtained in volcanic environments; consequently, most of the examples presented here deal with volcanoes. However, given the general nature of this paper and its focus on data processing and visualization, its contents are transferable and applicable to any study using SP data, expanding its usefulness to any user of the SP method.

\section{Overview of SP principles}

The SP method is based on the measurement of naturally occurring electrical potential differences in the earth. Some SP signals result from the presence of an electrical double layer at the microscale of a rock formation that is saturated to some degree with a pore fluid. In this case, we typically assume that the electrokinetic effect that occurs in such a system is the dominant signal-generating mechanism; an assumption that is often valid in most geoscientific settings (e.g., Leroy and Revil, 2004; Revil and Jardani, 2013). However, it is important to realize that other contributions to the generation of the SP signal exist, including the thermoelectric effect (Nourbehecht, 1963; Sill, 1983), which can be significant in environments with strong thermal gradients, such as geothermal fields or active volcanoes. In addition, SP signals with an electrochemical origin can be generated by redox potentials associated with ore bodies or the metallic casing of boreholes or contaminant plumes that are rich in organic matter (Sato and Mooney, 1960; Linde and Revil, 2007; Minsley, 1997; Castermant et al., 2008). Another contribution is the rapid fluid disruption effect described by Johnston et al. (2001) based on the previous works by Blanchard (1964) in nonporous media. They propose that charge generation by fluid vaporization/disruption contribute to the SP signal. Because liquids are vaporized or removed as droplets by gas transport away from hot sources, charge generation and local increase in electrical resistivity by removal of fluids should occur and contribute to electric fields. However, this new SP source has been criticized and might be explained by the electrokinetic effect (Revil, 2002).

\section{Field acquisition}

All of the measurements performed along a continuous line are hereafter called "profile." To perform SP measurements, we use a pair of nonpolarizable electrodes - usually $\mathrm{Cu} / \mathrm{CuSO}_{4}$ electrodes. The Petiau electrodes (Petiau, 2000) are considered more stable for longterm monitoring, but $\mathrm{Cu} / \mathrm{CuSO}_{4}$ electrodes offer many benefits for field prospecting as well as with respect to their design, such as a low price and easy homemade construction. They provide an enhanced electrical contact with the ground due to a greater porous surface, and they allow us to improve percolation by manually increasing the pressure of the electrolyte inside the electrode as the operator pushes the rubber plug of the electrode. The porous pot electrodes such as those used for magnetotelluric measurements have a bigger diameter than "slim" pencil-shape SP electrodes, and they theoretically offer a slightly greater or similar porous surface. However, due to their flat base, any imperfection of the ground will lift and tilt the electrode, resulting in a significant worsening of the contact (thereby increasing the contact resistance) if not noticed or if not corrected. The pencil-shape electrodes have sharp or slightly rounded preeminent porous tips that allow for optimization of the surface of contact. In volcanic fields, in which the ground is often rocky and irregular, the problem with "porous pots" is common, and we have found that pencil-shape electrodes allow for getting a good electrical contact, quickly and easily. With SP prospection, in which many measurements are done each day, this is all the more important. $\mathrm{Cu} / \mathrm{CuSO}_{4}$ electrodes have been used for the examples presented in this paper. The microporous end of these electrodes is made of permeable wood (or ceramic), which is put into contact with the ground (Figure 1). Wood with high permeability is preferred over ceramics due to its durability and because it ensures better percolation and thus better electrical contact.

The difference in the electrical potential between the reference electrode (arbitrarily placed at the beginning of the profile) and the moving electrode is measured with a high-impedance multimeter, and it is typically 
in the order of a few millivolts up to a few tens of millivolts. Before each SP survey, it is important to check that the multimeter is operating properly. Malfunction arises from aging of the electronic components or from infiltration of water inside the multimeter during fieldwork. Two types of tests can be done to ensure that the multimeters are properly working: (1) a test using a current calibrator in the laboratory or (2) the comparison of the measured values for at least three different multimeters, for the same measurement in the field: The three multimeters must show the same SP value. Note that it is very important to always connect the moving electrode to the positive port (VDC) of the multimeter and the reference electrode (through the connection on the wire reel) to the negative port (COM). Keeping this convention in mind is of utmost importance to interpret the relative positive and negative peaks correctly.

A long wire (usually approximately $320 \mathrm{~m}$, approximately $420 \mathrm{~m}$, or approximately $520 \mathrm{~m}$ ) is used to connect the two electrodes to the multimeter. These are deliberately not chosen as exact multiples of $100 \mathrm{~m}$ to allow for tying the cable at the beginning of the profile to something heavy or immovable, as well as to use the extra wire to potentially move the new reference location, in the case of a bad electrode-soil contact at the end of the profile. For example, $320 \mathrm{~m}$ of cable corresponds to a usual $300 \mathrm{~m}$ measurement profile in addition to having $10 \mathrm{~m}$ of extra cable on both ends. The core of the wire that we usually use is made of copper, and its section is usually of $1.5 \mathrm{~mm}^{2}$. We did not notice

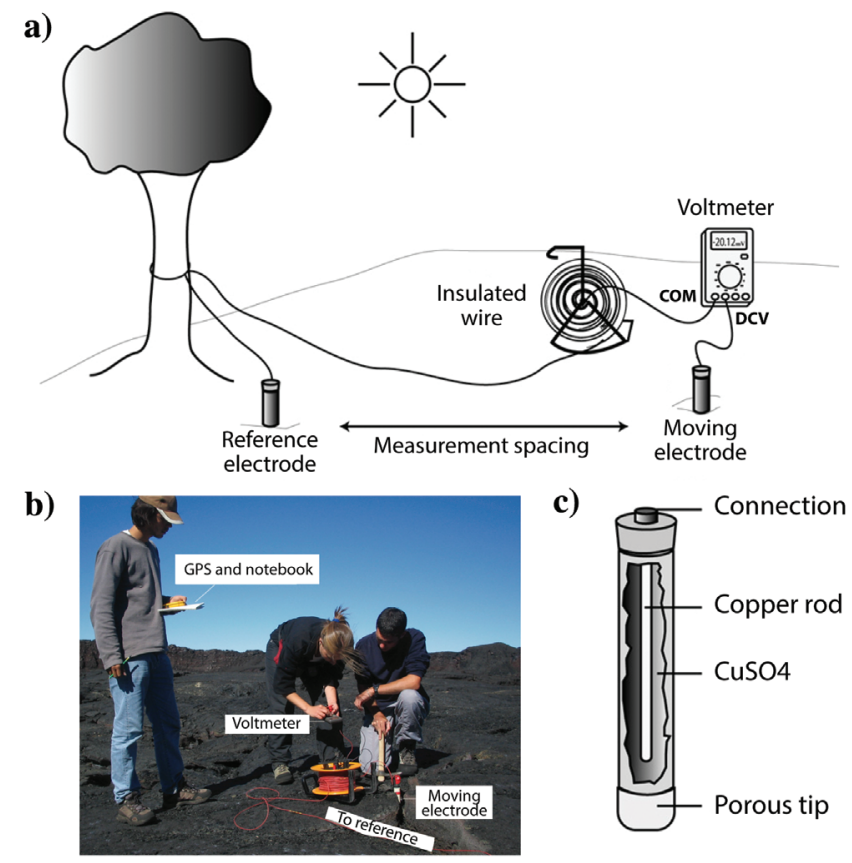

Figure 1. (a) Schematic representation of SP data acquisition. COM and DCV indicate the correct connection to the multi meter. (b) Example of field data acquisition (photo courtesy A. Finizola). (c) Schematic representation of a $\mathrm{Cu} \mathrm{CuSO}_{4}$ non polarizable electrode (modified from Barde Cabusson, 2007). any significant benefit or drawback in using a thinner or thicker wire on the SP measurement itself. However, with these characteristics, a $300 \mathrm{~m}$ wire appears to have a good weight/efficiency ratio avoiding heavy coils of wire in the field, especially in uneven or otherwise challenging terrains, while still enabling the coverage of long distances in the field without having to change the reference too often. Using a long wire (several hundreds of meters) allows us to reduce possible errors that may occur due to a too-frequent change of the reference (fixed) electrode. Reducing the number of reference changes during a survey is recommended to reduce possible differences between sections (e.g., noise), associated with different environmental conditions at each reference. This is usually insignificant, but we can reduce the risk by using a long wire, thereby minimizing the amount of required reference changes. The length of the wire obviously has a trade-off as well because, the longer the wire, the harder it becomes in rough terrain to carry and to roll-collect the wire for the subsequent section of the profile; for long wires, the chance of it getting stuck behind vegetation, rough rock surfaces, etc., becomes higher. In inhabited areas, it is also important to take into account that the longer the wire, the higher the electrical noise. The spacing between two successive measurement points depends on the size of the anomalies that we expect. Commonly, spacing of $20 \mathrm{~m}$ is optimal to get good resolution, that is, adapted to the detection of the main structural limits, hydrothermal anomalies, and hydrogeologic flows (Finizola et al., 2002, 2003; Bennati et al., 2011), while ensuring reasonable data acquisition time on areas of several square kilometers. To save time and maintain the precision of the spacing between measurements, the cable can be marked with pieces of colored tape, with the number of marks corresponding to the distances from the last reference, for example, the first five marks $=0 \mathrm{~m}$, one mark $=20 \mathrm{~m}$ from the reference, two marks $=40 \mathrm{~m}$, three marks $=60 \mathrm{~m}$, four marks $=80 \mathrm{~m}$, five marks again $=100 \mathrm{~m}$, one mark again $=120 \mathrm{~m}$, and so on. At each measurement location, a small hole (approximately $10 \mathrm{~cm}$ deep) is dug to reach the natural moisture of the soil and thus to improve the electrical contact between the electrode and the ground. As an alternative to the fixed reference acquisition method, the gradient method consists of moving both electrodes forward along the profile at each measurement, with a constant measurement spacing (e.g., Thanassoulas, 1989; Minsley, 1997; Lowrie, 2007). However, this method increases the chances of one of those electrodes having a bad contact resistance for the next measurement, increasing the risk to impact all the consecutive measurements it is connected to. To reduce this risk, the leading electrode can also become the trailing electrode at each new measurement. This technique can be used to minimize errors but the gradient method anyway involves significant cumulative errors on long distances, compared to the fixed reference electrode acquisition technique. Repeating each measurement at least three times at each station helps to reduce the error 
but does not cancel it and adds significantly to the time necessary at each measurement point. This is critical for survey areas of several square kilometers, where thousands of measurements are necessary. The gradient method should thus be used with extreme caution in small-dimension surveys with no or very limited environmental noise. With a long wire, switching the electrodes at each new reference is performed to keep the electrode located at the last measurement untouched in the ground while starting with the next section of measurements. This minimizes the risk to worsen the contact without noticing it. It also compensates for the small difference of potential possibly existing between the two electrodes themselves. The significantly lower noise affecting the data with the fixed-base method (with respect to the gradient method) is crucial in studies involving the repetition of measurements in time, for example, to monitor the evolution of the SP signal along a profile. Chaput et al. (2019) show the reproducibility of their SP measurements in areas not affected by variations of the hydrothermal or hydrogeologic activity, whereas the method allows for detecting some variations from a few millivolts to several tens of millivolts, mapping a caldera collapse before the collapse with $1 \mathrm{~m}$ of precision. With the noise affecting the signal with the gradient method, such precision would be lost.

Water or a bentonite/water/salt water mixture can be used to improve the contact resistance when the ground is particularly dry, but this is usually unnecessary. The natural moisture of the ground is generally sufficient to provide a good coupling, and the use of a high-impedance multimeter allows for getting goodquality measurements even with varying contact resistances from point to point. For SP, one can even argue that the artificial wetting of the ground is not recommended: It can change the local geochemistry and electrical double-layer effects that are at the foundation of the SP coupling, and these changes may therefore erroneously impact the SP measurement. Therefore, we would only recommend using wetting of some kind in case everything else fails. From a practical point of view, measurements should be planned beginning at the higher elevation and ending downslope. This makes the winding of the wire significantly easier and faster because the weight of the wire itself would otherwise increase the friction with the ground, whereas, going downhill, gravity will actually help in pulling this weight.

With $\mathrm{Cu} / \mathrm{CuSO}_{4}$ (and other nonpolarizable) electrodes, two main techniques exist to ensure the quality of the SP data. The first option is to perform several SP measurements in a small area for each data point; this method can be used for any electrode type, but it is time consuming and does not ensure a real control on the quality of the electrical contact. In addition, there is the ambiguity of which SP value to choose. The repeated measurement technique is a good practice for the reference electrode change at the end of a section of wire, in complement of the second option presented thereafter. The second option is to measure the value of the elec- trical resistance prior to each SP measurement to check the electrical contact between the electrodes. This second option allows for getting a direct assessment of the quality of the electrical contact, and it significantly reduces the duration of each measurement. This is applicable only to nonpolarized electrodes because other electrode types would need a sometimes long relaxation time and, in the long term, become permanently polarized. Usually, the resistance should be on the order of a few kilo ohms or tens of kilo ohms. If the resistance is much higher, the first verification consists of checking the wires connected to the multimeter by creating a closed circuit with the wire and checking for a maximum resistance of only a few ohms. Usually, the contact of the moving electrode with the ground should be enhanced when reaching a few hundred kilo ohms or, alternatively, the location of the measurement should be modified by a few tens of centimeters if the resistance value exceeds approximately 1 mega ohm. These threshold values are indicative of and closely depend on the geologic nature of the surface or subsurface and the moisture of the ground. When the resistance measurement is satisfying, the SP measurement can be made by switching the multimeter to the VDC position. The operator should read the value when it is stable (usually after a few seconds for nonpolarizable electrodes). In the case of doubtful SP values, problems regarding the quality of the SP data can be easily detected when, while making several measurements, the SP variation appears to be directly linked to the resistance variation. In that case, the electrode needs to be moved to another location. However, risks of malfunctioning of the instrumentation are usually easy to detect and mitigate because of the several tests and checks done during a survey and during the preparation of the survey: (1) Before the survey, each wire and each pair of electrodes are checked carefully for a good electrical connection, (2) each multimeter that is used is calibrated with a current calibrator or, if one is not available, some measurements are performed in the field at the same location using different multimeters to check their accuracy, (3) at the beginning of every day in the field, the electrodes are placed tip to tip to check for an electrical potential difference of less than $1 \mathrm{mV}$, and (4) if any sudden variation of the SP value occurs in the field, we perform repeated measurements in a space of a few centimeters and some instrument checks are done again. Each measurement location is registered with a handheld GPS and recorded along with the measurement numbering, the distance from the initial reference, the measured resistance, and the measured SP value. A good practice is to keep the electrodes, and in particular the reference electrode, protected from direct sunlight to avoid possible disruptions due to temperature variations and rapid evaporation of the electrolyte from the electrodes. SP data have to be collected when the moisture of the ground is good enough in the first few centimeters of the ground. We usually dig a maximum of $10-15 \mathrm{~cm}$, 
and at that scale, the vertical electrical field gradient is lower than SP environmental noise (Boudoire et al., 2018; Chaput et al., 2019). If the electrode contact is satisfying, there is no reason to dig more than $15 \mathrm{~cm}$ in depth for SP mapping. If the contact is not satisfying in the shallow part of the ground, it is better to postpone a survey to a rainier season.

A new reference station is established every time the end of the wire is reached. At the last measurement along the wire, the moving electrode is left in place in the ground to become the new reference electrode and the former reference electrode that stayed at the beginning of the profile is picked up and is then used as the moving electrode for the next section, until the end of the wire is reached again. Using this technique helps to avoid error accumulations related to the potential difference existing between the two electrodes put tip to tip, that is, the error induced by the electrodes themselves. This error is very small but can accumulate if the reference and measuring electrodes are not switched at each section. Switching ensures that the electrode error cancels out over two sections (one section corresponds to the length of the wire). $\mathrm{Al}-$ ternatively, the potential difference between the two electrodes can be measured regularly and the data can be corrected from the measured value. Note that after switching, the previous reference electrode becomes a moving electrode and must be connected to the positive port (VDC) of the multimeter, whereas the moving electrode becomes the new reference and must therefore be connected to the negative port (COM) through the coil of wire.

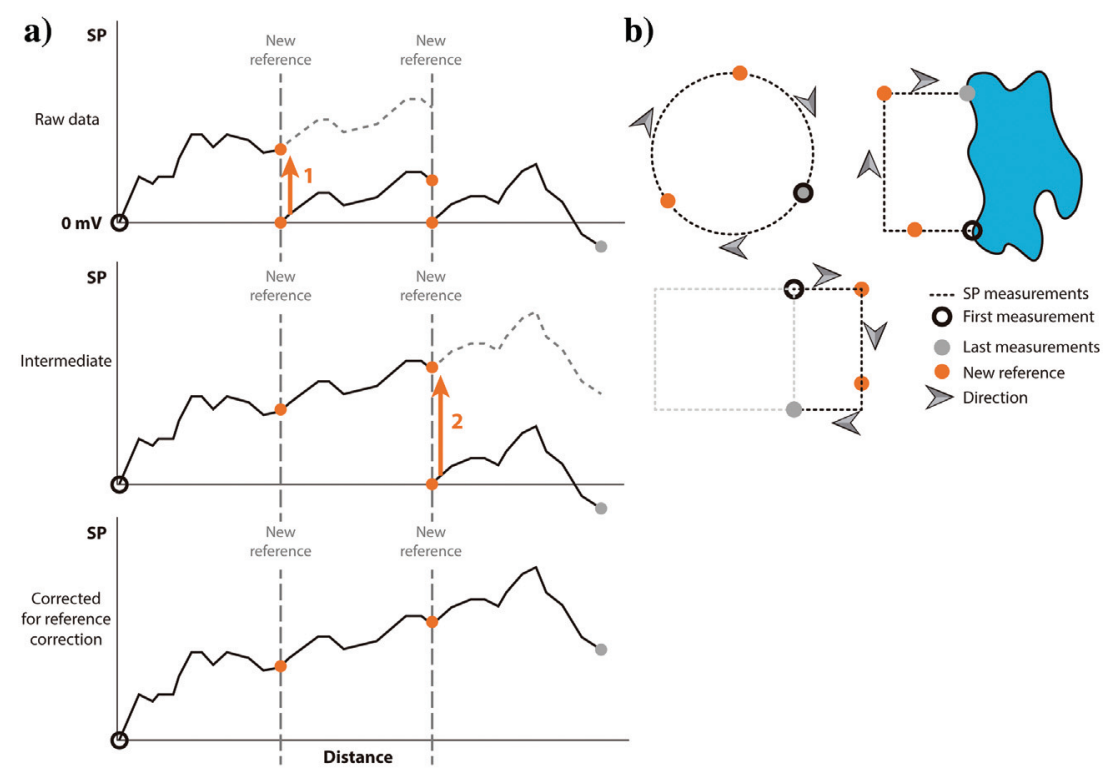

Figure 2. (a) Schematic representation of the reference correction of SP data. The orange arrows represent the shift of the data, section by section. This must be applied to any SP profile composed of several sections, that is, with several references, for example, those presented in (b) (SP profiles in an aerial view). (b) Schematic representation of a profile closed on itself, on the sea at both ends, or on any other SP profile.
The whole measurement network of an SP survey has to be interconnected. To do so, SP measurements are performed forming loops, that is, closed profiles or profiles that are connected at both ends to other closed profiles (Figure 2b). During data processing, this will allow for assessment and correction of the drift undergone during the acquisition of the data. The only exception to closed-loop acquisition is for the "floating profiles" that are connected to the main network by only one end, or for single isolated profiles that are measured in a short time period (of a few hours maximum) for which we typically can assume that no significant modification of the environmental conditions takes place. However, this should be done only exceptionally and only when closing the profile is absolutely not possible. A profile connected at both ends to a single water body is also considered a closed profile, considering that this water body is an equipotential surface (Figure 2b). This is true if we consider that the $\mathrm{pH}$ and mineral composition are reasonably similar in the whole water body. In general, it is thus preferable to close the profiles at the same geographic location. By convention, the $0 \mathrm{mV} \mathrm{SP}$ value is generally attributed to the sea, a lake, or surface of an aquifer, and a positive or negative SP anomaly will refer to an anomaly with respect to this body. In the case of the absence of any water body in the investigated area, the $0 \mathrm{mV}$ potential is taken arbitrarily. This can be an area located outside or at the margin of the sector where the main study is focused (where SP variations are expected to be minor) or where the values are approximately the average of the data set.

After the survey, all of the SP values of the interconnected profiles are corrected through several steps that will connect the whole data set to a unique reference station (e.g., with respect to the sea or any other main water body of the investigated area, when possible), which is set to $0 \mathrm{mV}$. This process requires two consecutive corrections of the raw SP data: (1) the reference correction and (2) the closure (or loop, or drift) correction. We use a spreadsheet application, such as Excel or Grapher (Golden Software), to process the data, and we use a contouring and $3 \mathrm{D}$ surface mapping program to interpolate the data and create maps and graphics (e.g., overlaying the 2D SP map on a 3D surface) for the visual presentation and evaluation of the results. Besides maps, the data can be displayed using plots (graphs) as well. In a plot, the SP data are presented as a function of the acquisition distance to, for example, precisely locate structural features, or as a function of the altitude to, for example, highlight areas with different geology or hydrogeologic or hydrothermal characteristics. 


\section{Corrections of an SP profile Reference correction}

During acquisition of the data, each time that we arrive at the end of the wire with the moving electrode (which would define one section of a profile), a new reference electrode is established, that is, the last position of the moving electrode will become the new reference station for the next section, until the end of the wire is reached again. The new reference is considered to be the new $0 \mathrm{mV}$ reference for the whole new section (Figure 2), relative to which all other measurements of that section are made. Therefore, we obtain data with several arbitrary $0 \mathrm{mV}$ values, at the beginning of each new section of a profile, which must be properly combined and corrected to obtain continuity in the data set along each profile. In other words, the reference correction is applied to connect all of the sections of a single SP profile together. It must be applied for each SP profile, section by section, to connect each section to the end of the previous one. Only the first section will remain unchanged, whereas the others will be corrected section by section along the direction in which the measurements were acquired. This correction allows us to link all of the sections of one profile to the same initial reference potential $(0 \mathrm{mV}$ at the beginning of the profile).

Let us now take a closer look at how we can bring these theoretical concepts to practice. In a spreadsheet, we isolate each profile in individual worksheets (Figure 3). We want to highlight that the formulas used are transferable to any (open-source) spreadsheet software. The reference correction is made on each profile separately, section by section. In the column containing the raw SP data, the first section is not modified and the last value of this section is added to all of the measurements of the second section. Thereafter, the third section is shifted by the last corrected value of the second section and so on. In the example of Figure 3, the locations of the references are highlighted by the orange rows and correspond to a data acquisition length of $300 \mathrm{~m}$ (the maximum length of the wire) per section. As pointed out previously, the initial section (rows 3-18 in this example) depends directly on the first reference so no correction is applied to these data points. The second section (from rows 19 to 33 ) is shifted to the last value of the initial section; section 3 (rows $34-48$ ) is shifted to the last value of section 2.

\section{Closure (or loop, or drift) correction for one profile}

In the case of a closed profile, the first point is geographically the same as the last one: The measured SP value should theoretically be the same as the well. This would be true if no environmental perturbations occurred within the time span when the first and last measurements were made. However, during a survey, the measurement conditions can change (e.g., rain events inducing variations in the soil moisture, the soil temperature, instrument error such as the progressive increase of potential between the two electrodes themselves, etc.); consequently, a drift in the measurements will be observed.

Without any other prior information, we assume that the drift increases linearly from the time when the first measurement was taken to the time of the last one; that is, along the period of time of the acquisition, the drift increases continuously. It remains difficult to provide a very accurate correction due to the variability of events provoking the drift. Among those, localized rain events that may affect only part of a profile (in particular in the case of kilometer-long profiles), variations of the hydrothermal activity (in geothermal fields and volcanoes), and spatiotemporal variations of the sun radiation, which are all nonlinear variations. Thus, we consider that the most efficient approximation, in terms of accuracy and acquisition and processing times, is to use the

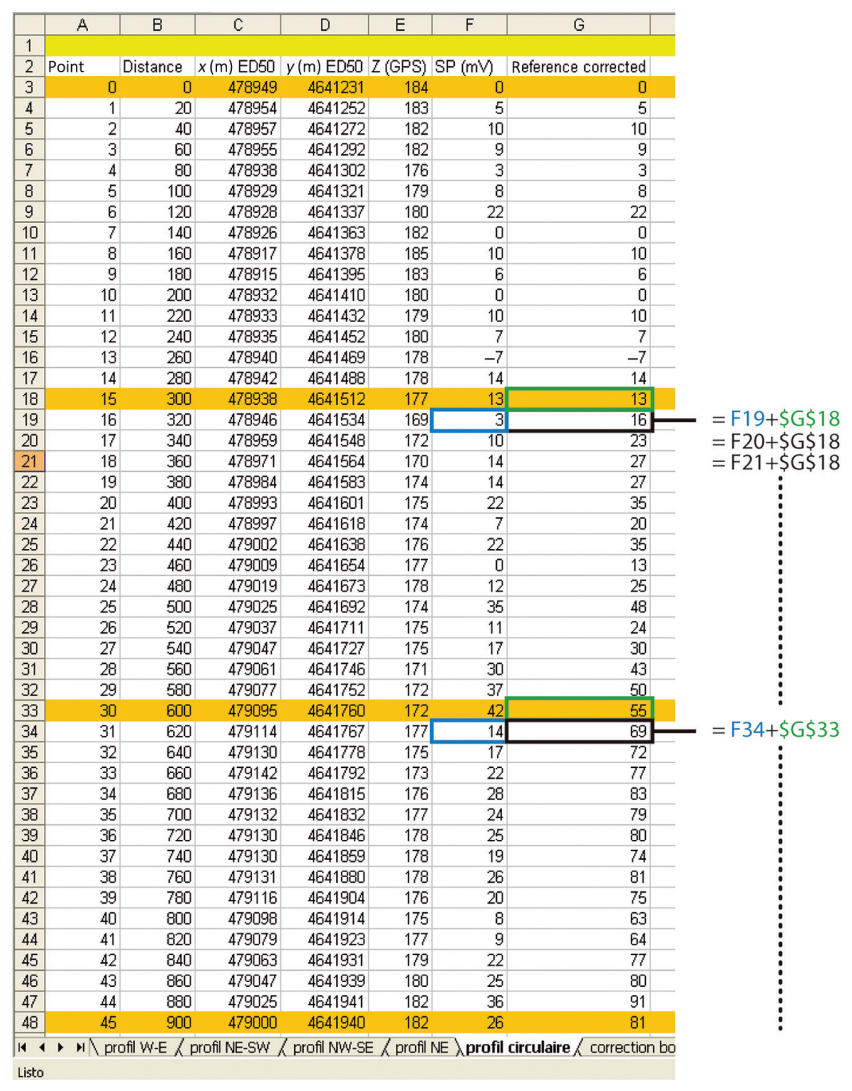

Figure 3. Reference correction of the SP data along a single profile, using Microsoft Excel. The references locations and values are highlighted by the orange rows that mark the limits of each section of $300 \mathrm{~m}$ (the maximum length of the wire in this example). The initial section (rows 3 18) does not need a reference correction (note that columns $\mathrm{F}$ and $\mathrm{G}$ are identical for that section). The second section (rows 1933 ) is added to the last value of the initial section. Likewise, section 3 (rows 3448 ) is added to the last value of section 2 . The $\$$ sign is the formula that is used in Excel to keep the cell coordinates (the column letter and the row number) constant when the for mula is copied through the rest of the section. However, any of those formulas are transferable to any other open source spreadsheet software. 
distance along the profile to distribute the drift. Usually, we expect a drift of a few millivolts in an SP loop acquired over the duration of a few hours without drastic variations of the environmental conditions (in particular, heavy rain), although loops performed over several days and with changing conditions may show drifts of several tens of millivolts. It remains difficult to identify the various phenomena producing the drift and to evaluate their individual contributions; regardless, it is considered parasitic and must be corrected through the closure correction.

In the example presented in Figure 4, we imagine a profile consisting of 10 measurement points, in which the last measurement point (10) is geographically the same as the reference (0), forming a closed profile (for examples of closed profiles, see Figure $2 b$ ), that is, the first and last measurement points that are either at the same location or are both linked by an isopotential line (e.g., sea, lake, and aquifer). The drift is defined by the difference between the SP values at the reference and

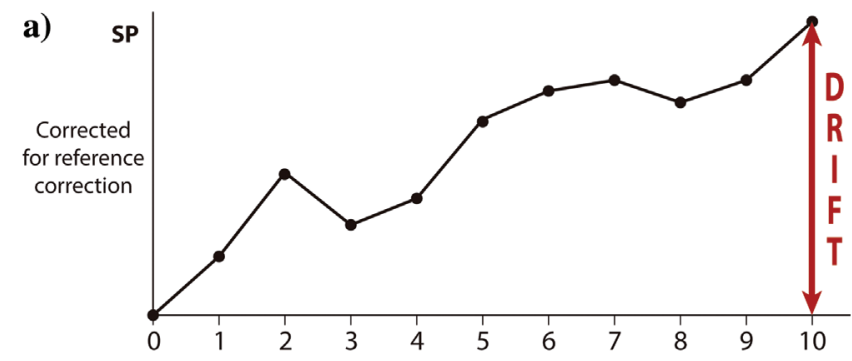

b)
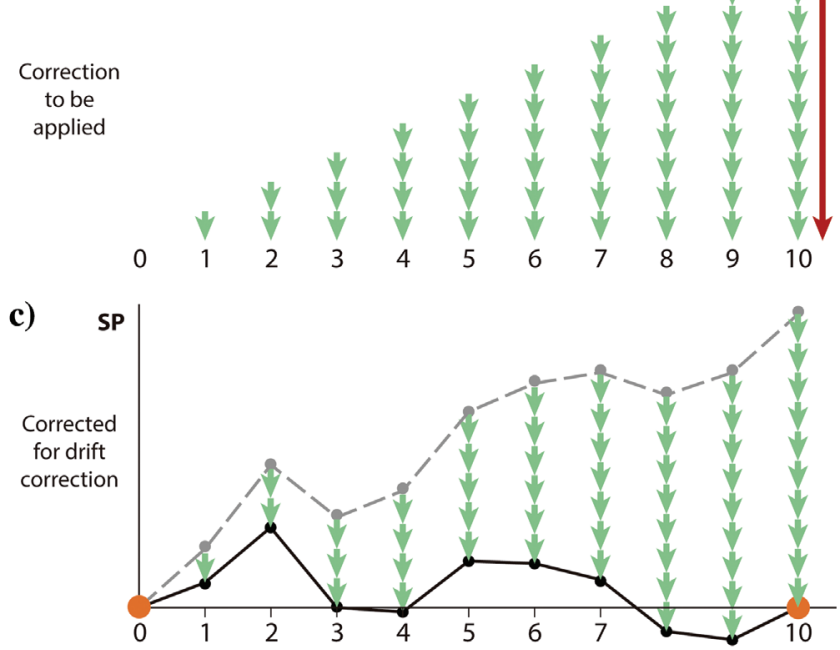

Figure 4. Schematic representation of (a) an SP profile com posed of 10 measurements in which points 0 and 10 are either geographically the same or are linked by an isopotential line (e.g., sea, lake, or aquifer); the difference observed in the SP value is the drift. (b) The linear distribution of the drift from the reference ( 0 fractions of the drift) to point 10 (10 fractions of the drift, i.e., the total drift), in which one green arrow is one fraction of the total drift. (c) The application of the clo sure correction for the 10 data points, with points 0 and 10 now displaying the same SP value. very last measurement point of the profile, after application of the reference correction (Figure 4a). The correction of this drift is applied to all of the data points of the profile by linearly increasing the correction factor from the first to the last point of the profile. The initial point is the reference of the profile so no correction is applied to it (considered as point 0 ). In our example of Figure 4, the first measurement point is corrected for one-tenth of the total drift, in which 10 is the total number of data points without counting the reference. The second point is corrected for two-tenths of the total drift, and so on until the last point. The last point is corrected for the total drift, resulting in it obtaining the same value as the initial point, as it is supposed to be.

Looking at a practical example of the aforementioned theoretical correction, the Excel spreadsheet presented in Figure 5 shows that the reference point (row 3) and the last point (row 48) have the same GPS coordinates but a different $S P$ value after reference correction (see cells G3 and G48). As said, this difference is the drift that we must correct the data for. The correction is presented in column $\mathrm{H}$, and the corresponding equation is shown on the right side of the figure.

First, we must create a column with continuous numeration of the data points, beginning at zero for the reference (column A). The numbers in this column will be used for determining the correction factor applied to each point. The reference itself does not need a closure (or drift) correction, which is why the correction factor for this SP value is zero (cell A3). The closure correction formula is first defined in cell $\mathrm{H} 48$, and this formula is applied across the column, up to the first reference point. We can immediately validate whether or not the formula has been applied correctly because the resulting value of the last data point (cell H48) should be identical to the value of the reference point (here $0 \mathrm{mV}$ ). Some elements of the equation are constant, but others vary as the correction is applied to each point of the profile.

The closure correction equation is

$$
\mathrm{SPc}=\operatorname{SPr}-(D / N) * n,
$$

where SPc is the SP value after the closure correction, $\mathrm{SPr}$ is the SP value after the reference correction, $D$ is the observed drift, $N$ is the total number of data points in the profile excluding the reference, and $n$ is the place of the data point in the profile, determining, together with $D$ and $N$, the correction factor.

In the example shown in Figure 5, the correction formula in Excel is composed as follows:

1) Drift

$$
D=\mathrm{G} 48-\mathrm{G} 3 .
$$

This is a constant in the equation for the whole profile, which is why we use the $\$$ sign that keeps the 
row or column following this sign unmodified when copying the formula to the top of the column.

2) Divide the drift by the number of data points in the profile ( $\boldsymbol{N}$; a constant)

$$
=(\mathrm{G} 48-\mathrm{G} 3) / \mathbf{A 4 8} \text {. }
$$

3) Multiply by the place of the data point in the profile ( $n$; variable)

$$
=((\mathrm{G} 48-\mathrm{G} 3) / \mathrm{A} 48) * \mathbf{A 4 8},
$$

where $n$ is a variable and A48 in our example corresponds to the closure correction applied to the last point of the profile. When copying the formula to the top of the column in the Excel sheet, the correction factor will change as a function of the row.

4) Subtract this value from the SP value for which the reference correction has already been applied (SPr)

$$
=\mathbf{G 4 8}-((\mathrm{G} 48-\mathrm{G} 3) / \mathrm{A} 48) * \mathrm{~A} 48 .
$$

\section{Closure correction for multiprofile surveys Overview}

As discussed before, in a complete SP survey, measurements are performed forming loops (closed profiles or interconnected profiles) to monitor the drift and correct for it. When a data set is composed of several profiles in an area to build an SP map, each profile must first be corrected independently for the reference correction, as described in the "Reference correction" section. In the following description, we assume that this reference correction has been applied to all of the profiles.

After the reference correction, each profile has its initial point as a reference with a value of $0 \mathrm{mV}$. To connect the data from all of the profiles together, we choose an initial closed profile/loop that will form the basis for the subsequent closure corrections of other closed profiles (see step 1 for Figure 7a-7d). Under optimal conditions, the initial loop should be completed in a short amount of time. However, it can be composed of measurements acquired over several days. This loop is the first to which the closure correction is applied,
This is also a variable that will change per data point.

Note that equation 3 gives the absolute value corresponding to the length of a single green arrow in Figure 4.

In a real case study (Figure 6), we observe that the closure correction affects the whole profile but does not affect the shape of the SP curve; that is, the maxima and minima remain geographically unchanged. The drift is exaggerated here, compared to the length of the profile, to get a perception of the effect of the closure correction. In a real case, the closure correction would usually be lower. However, performing the closure correction is important because even an uncorrected small drift can induce big artifacts on an SP map. The importance of the location of the SP maxima and minima will be discussed in the following sections. It is also important to keep in mind that the SP measurements are not absolute; after the application of the reference correction, the SP values are relative to the first reference of the profile that they belong to and, after the application of the closure correction, the values of the whole data set are relative values with respect to one unique reference that we choose out of the area of interest of the study or that is placed at the sea, a lake, or another water body.

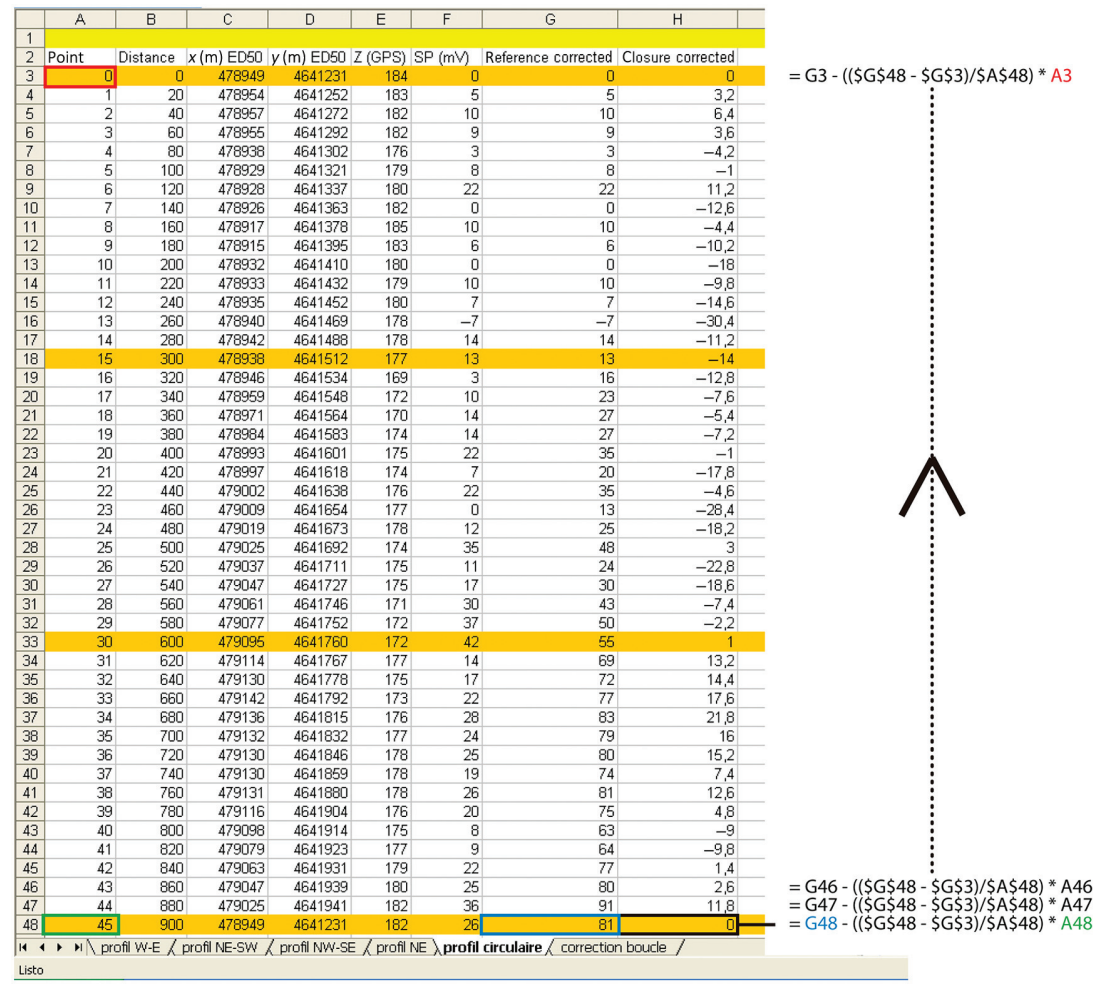

Figure 5. Closure correction of the SP data along one closed profile (or loop), using Excel. References are highlighted by the orange rows that mark the limits of each section of $300 \mathrm{~m}$ (the maximum length of the wire in this example). In column G, the first (cell G3) and the last (cell G48) SP measurements are at the same geographic location but they show different SP values (values after the reference correction). This difference (G48 G3) corresponds to the drift of this profile. Column $\mathrm{H}$ shows the closure correction applied to correct for this drift. When applied to the whole loop, the first (cell H3) and the last (cell H48) display the same SP value (here, $0 \mathrm{mV}$ ). The $\$$ sign is the formula that is used (in Excel) to keep the cell coordinates (the column letter and the row number) constant when the formula is copied through the rest of the column. 
which also gives a sense of the quality of the measurements; the other profiles have to be connected at both ends to this initial loop, or to another profile that is already corrected by the closure correction. Thus, the profiles are forming new loops and are connected step by step to parts of the survey for which the data have already undergone the closure correction. To optimize this procedure and to make sure proper data corrections can be made, a precise planning of SP data acquisition in the field always involves foreseeing the correction phase. This involves planning interconnected profiles and profiles that preferably do not cross each other. Profiles crossing each other create additional sections, each of which have to be processed as individual loops. The processing can therefore become timeconsuming. Moreover, each intersection of the profiles and, in general, each connection between different profiles of the SP survey should be performed at a common measuring point in the field. To do so, it is recommended to flag those connections points in the field (e.g., the references of each section can be marked by placing a flag or a discreet ring of stones) to be able to connect a new profile at the exact same measurement point of an older profile (i.e., using the same hole).

In the successive steps proposed in Figure 7, the black dotted lines are the data to which the closure correction has already been applied; steps a4, b4,

c)

d) c5, and $\mathrm{d} 5$ correspond to the complete data sets acquired in the field. The green sections are the loops connected step by step to the data that have already been corrected (the black sections) in a previous step. The a)

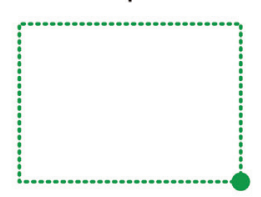

b)

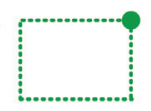

2
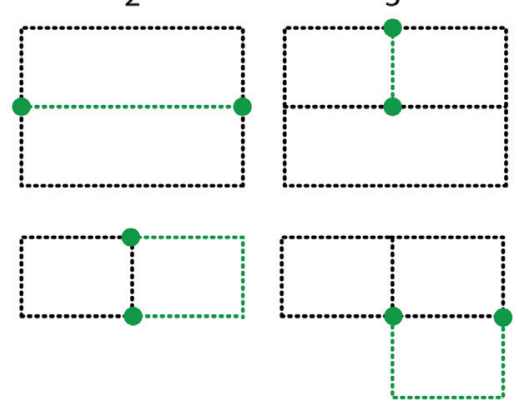

4
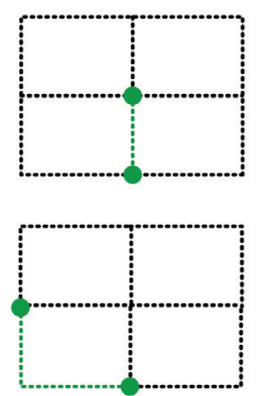
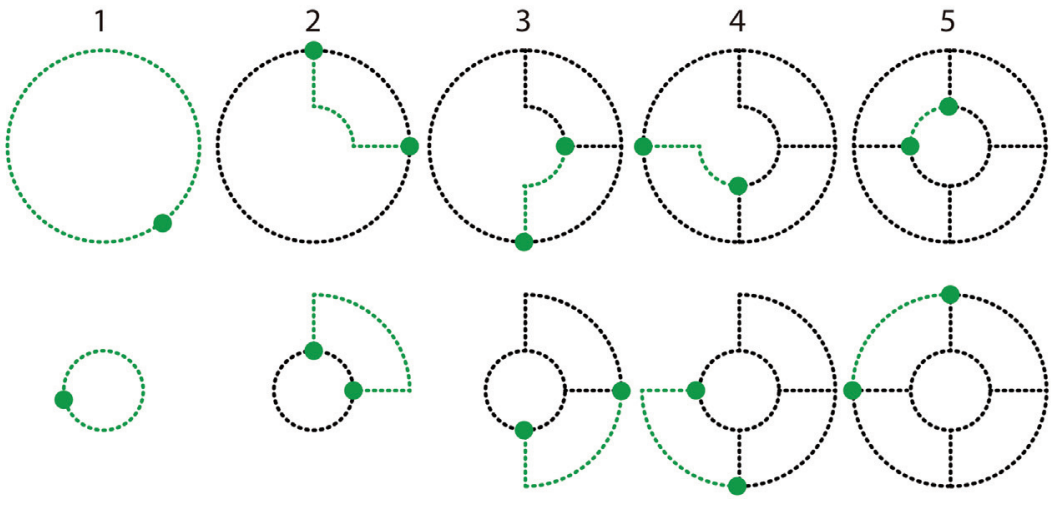

Figure 7. Two examples of simple data networks corrected by the closure correction. (a and b) Two alternatives of the closure correction for a simple grid. (c and d) Two alternatives of the closure correction for a "volcano type" net work, that is, circular profiles around the crater and the base of the cone + radial profiles on the flanks. In the successive steps, the black dotted lines are the data that have already been corrected. The green dotted lines are the data currently being corrected.

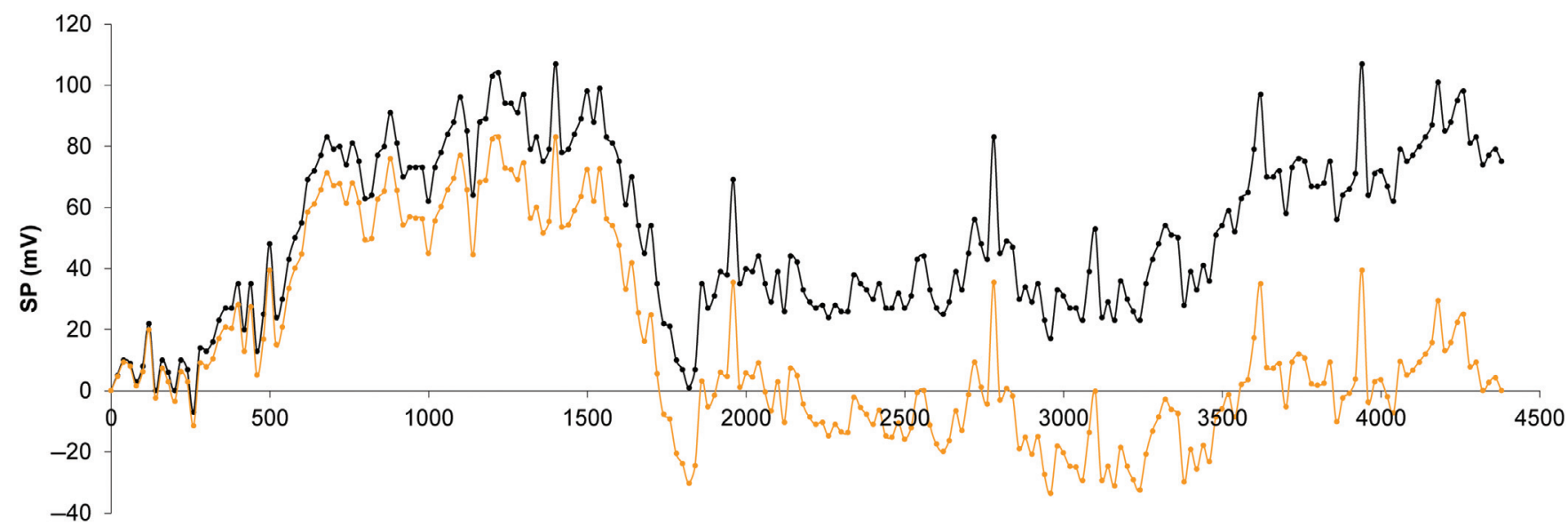

Distance $(\mathrm{m})$

Figure 6. Example of the closure correction for an actual closed SP profile. The black line is the data set that has been previously corrected for the reference correction, and the orange line is the same data set after the application of the closure correction. The drift is exaggerated here, compared to the length of the profile, to get a perception of the effect of the closure correction. Note that the last point (at a $4380 \mathrm{~m}$ distance) is corrected to reach the same value as the reference point (at a $0 \mathrm{~m}$ distance; that is geo graphically the same point because it is a closed profile). Also note how this correction changes the SP values gradually without affecting the location of the SP maxima and minima. 
rule to keep in mind is that after being corrected for the closure correction, a data point is fixed and its value with respect to the unique reference of the data set cannot be modified during the following steps of data processing.

\section{Connect a new loop to already-corrected data}

As discussed before, after the reference correction, all the individual profiles have their reference (the first point of the profile) at $0 \mathrm{mV}$. After the first step of the closure correction (see the "Closure [or loop, or drift] correction for one profile" section and the "Overview" section), we choose a second loop to be corrected. Because the reference was set arbitrarily to $0 \mathrm{mV}$, the SP values at the connections between the two loops are not equal (Figure 8a). We first have to connect one extremity of the new loop (the green line in Figure 8) to the data that have previously been corrected (the black line in Figure 8) following a similar procedure as the one described in the "Closure (or loop, or drift) correction for one profile" section for the reference correction. For that purpose, the SP value difference at the intersection is added to all data points of the new profile such that this extremity of the new profile/loop has an SP value equal to one at the same geographic point in the already-corrected data. In our example (Figure 8), $4 \mathrm{mV}$ is added to each measurement point of the green loop to make the value of the first point coincide with the black, already-corrected loop (Figure 8b). After this operation, the electrical potential difference remains the same between each measurement point and the reference of the profile; that is, the same value has been added to each data point of the profile.

In Figure 8b, we observe that, after connecting the data of the new loop (i.e., adding the difference in SP values of the connection point to the whole profile), the SP values of the other extremity are not equal to the same geographic point in the initial black loop. This observed SP difference is the drift that must be distributed along the new profile (see the "Closure [or loop, or drift] correction for one profile" section). Figure $8 c$ shows the final result of the closure correction with the two ends of the new loop displaying the same SP value as those initially encountered at the same locations on the black loop (Figure 8a). In the spreadsheet (Figure 9), we first have to add the SP value from the already-corrected loop at the connection, to all points of the new loop (loop 2). Successively, the drift is distributed such that the two extremities of the newly corrected loop (K2 and $\mathrm{K} 6$ ) display the same SP values as the reference loop for these identical geographic locations (D3 and D7; see also Figure 8c). From this step onward, the data belonging to this loop are fixed and can be used as data points to which other loops can be connected in subsequent steps of the closure correction procedure, as schematically displayed in Figure 7.

The closure correction of a multiprofile survey can be summarized as follows:
Step 1) Correct an initial loop 1, which is a closed profile or a profile connected at both extremities to the same equipotential surface (e.g., the sea).

Step 2) Connect a second loop (loop 2) to loop 1 by choosing one of the two extremities of loop 2 coinciding geographically with a point of loop 1 . The SP value will have to match the SP value of loop 1 at the connection location: This is done by adding or subtracting the adequate $\mathrm{SP}$ value to all of the data point of loop 2.

Step 3) Distribute the drift along this new loop.

Steps 4 and 5) Connect the next loop to the alreadycorrected data (e.g., at step 4, loop 1 and loop 2); that is, choose the next loop to be corrected from the remaining, uncorrected data, and apply steps 2 and 3 to this new selected loop. The data that have already been corrected for the closure correction are fixed and do not change. This step is repeated until the whole data set is properly combined and corrected for the closure correction.

For practical reasons, a survey does not necessarily start at the point that ultimately will be considered as

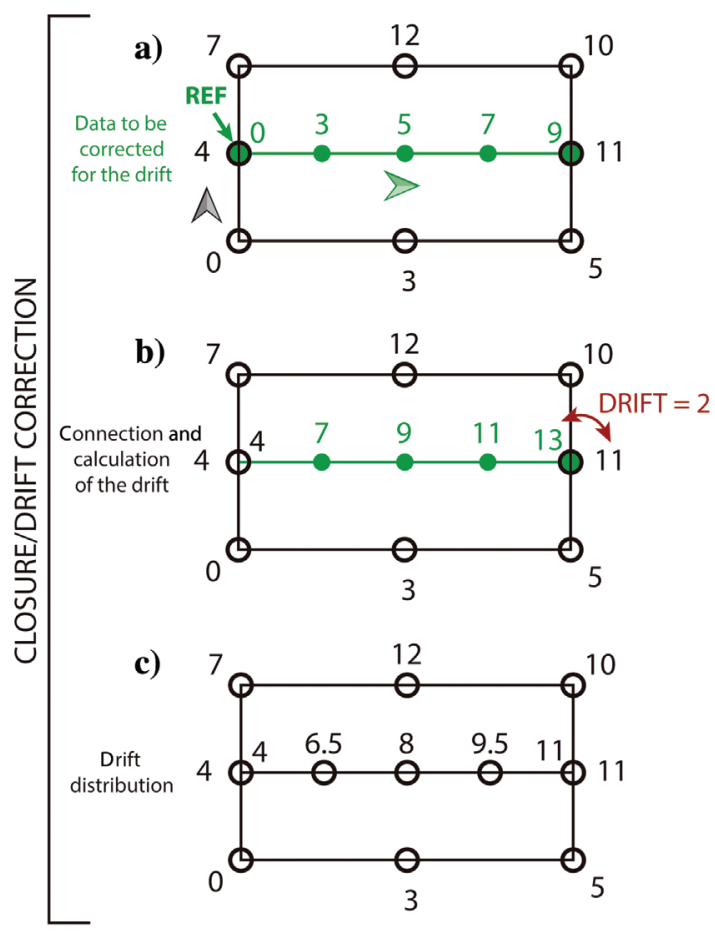

Figure 8. Schematic decomposition of the closure correction in a data set of two profiles. The black circles are data points already corrected for the closure correction. The green dots are the data to be corrected for the closure correction. The numbers correspond to the SP values for each data point (in $\mathrm{mV}$ ). (a) The two tone arrowheads represent the progres sion of the measurements in the field, and REF refers to the reference (or initial point) of the new profile. The first step (a and b) consists of connecting a new profile to a corrected one, and the second step (b and c) consists of the repartition of the drift along the new profile. 
the unique reference of the SP data set. When the reference and closure corrections have been applied to all collected data, the last step thus consists of assigning a $0 \mathrm{mV}$ value to the point that we choose as the final, unique reference of the data set. Preferably, this point should be located at a water body existing in the study area (sea, lake, or aquifer) or at any particular measurement point where no major SP variation is observed. During this last step, we add or subtract the SP value of the chosen point to the whole SP data set, so that this point will be $0 \mathrm{mV}$ and the relative SP values from one point to another do not change.

Finally, the SP values can be copied to a new Excel sheet along with a numbering column corresponding to the data points, the GPS coordinates, the names of the profiles, and any other information that the user may want to use when presenting the data. These SP values are the final product of the data processing and can be used to visualize the data.

\section{Data visualization and interpretation}

Now that we have successfully processed the raw SP data, we can visualize the SP anomalies.

With relatively small measurement spacing, data plots/graphs can provide detailed information. However, with a data set well distributed in the field, we can also present SP data in maps, using a gridding/interpolation, contouring, and surface mapping program. The small measurement spacing and the great spatial coverage give valuable information on different levels. This section does not intend to detail all possible interpretations of SP anomalies. Other publications already

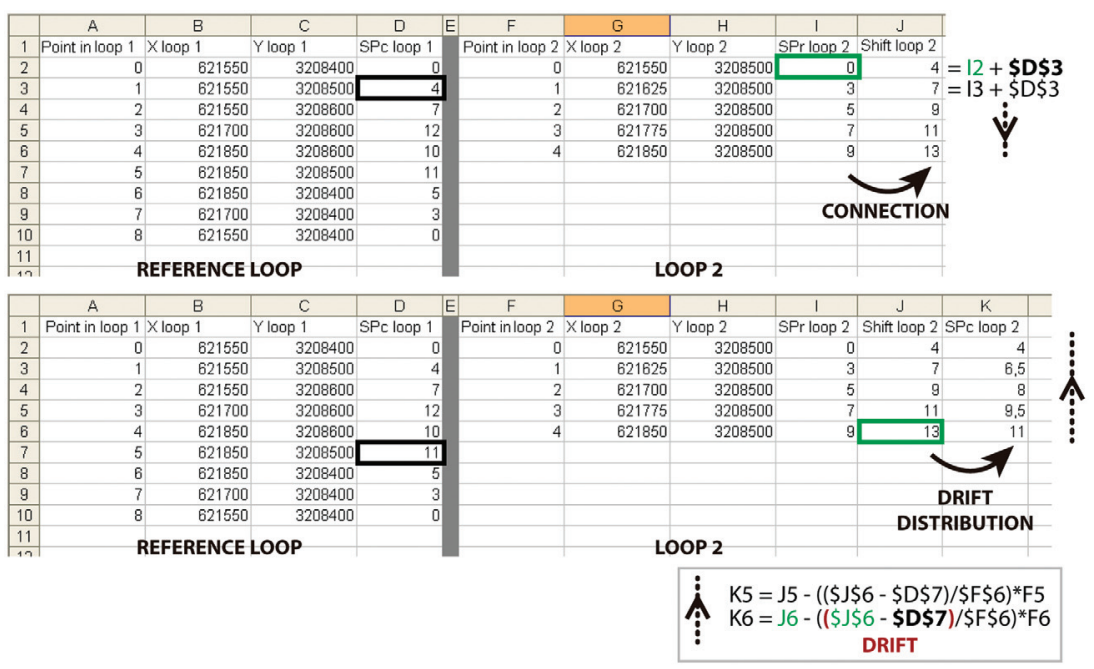

Figure 9. Closure correction of the SP data for the example schematically dis played in Figure 8. Loop 1 is the reference initial loop (the black color in Fig ure 8), and loop 2 is the new loop (to be corrected; the green color in Figure 8). The upper part of the figure refers to the connection of the SP data performed by adding the intersection SP value from loop 1, to all data points of loop 2 (i.e., connecting the data). The lower part corresponds to the drift distribution. The $\$$ sign is the formula that is used (in Excel) to keep the cell coordinates (the column letter and the row number) constant when the formula is copied through the rest of the column. give a good idea of the meaning of some SP anomalies in different contexts (e.g., Zlotnicki and Nishida, 2003; Jouniaux et al., 2009; Grobbe and Barde-Cabusson, 2019). This section aims to give an overview of the various possibilities to visualize SP data and extract useful information, including a discussion on some common elements of the interpretation of SP anomalies in environmental science studies.

\section{SP maps}

SP data files contain data acquired in the field, often with an irregular geographic distribution. These data must be converted into an evenly spaced grid before ing able to create a map representation. A grid file ains a list of $Z$ values (here, our SP data), and spatial position assigned to each value into the grid corresponds to the $x$ and $y$ geographic coordinates of the data points in the field. To create the grid and the corresponding SP map, we use dedicated data mapping, modeling, and analysis software. The input data file is a worksheet or text file in which all of the corrected SP are presented in one column. The corresponding $x$ $y$ coordinates fill two other columns. The workcan contain title rows and other columns that may exe to label the data points. For example, an addipere numeration of individual from a fis use transfering the data from a field notebook to (he GPS can also occasionally have low precision in if the coordinates are not corrected. A good idea is to create a graph of the geographic coordinates of the data points, labeled with the numeration of individual profiles. A missing or misplaced point along a profile usually corresponds to a mistake in its coordinates that can be corrected directly in the data set. This check can sound trivial, but it avoids important mistakes when the data are interpolate, and it especially helps to avoid the interpretation of SP anomalies that are actually artifacts. When the data set has been quality-controlled accordingly, it is ready for the gridding procedure.

As mentioned before, SP mapping in uneven terrains (i.e., having slopes, depressions, rivers, and inhabited areas), as is the case most of the time, results in data sets with heterogeneous spatial coverage. As a result, on the one hand, we obtain small measurement spacings (usually $20 \mathrm{~m}$ or less) along each profile, whereas, on the other hand, profiles are sometimes separated several hundreds of meters from each other. The gaps between profiles can be significant, and a single interpolation of the data can lead to the appearance of artifacts that can 
be visually misleading for the interpretation of SP maps. Although many gridding and filtering methods exist, a solution to minimize the effect of heterogeneous data coverage is to perform a double interpolation of the data set (Figure 10). Kriging usually creates some artifacts on the resulting map. These artifacts are often due to the limited search neighborhood typically used, as described by Neufeld and Wilde (2005). The authors proposed the use of all of the samples for kriging to generate artifact-free maps. For data interpolations to generate SP maps, we thus suggest using a very large radius of interpolation encompassing approximately half of all of the data set (e.g., a $1 \mathrm{~km}$ radius or more for the SP data of our Stromboli volcano example), with four sectors of search (northeast, northwest, southwest, and southeast quarters), a maximum of 64 data points to use from all the sectors, and a maximum of 16 data points to use from each sector. With a reduced radius of search, artifacts appear between the measurement profiles independently of any kriging/variogram options used. Moreover, kriging can be significantly affected by the choice of variogram model (Gorsich and Genton, 2000; McClean and Evans, 2000; Pyrcz and Deutsch, 2001; Leuangthong and Deutsch, 2004). To avoid any subjective selection of a variogram model, we suggest using double linear interpolation as a simple and effective method. It consists of two steps of (1) creating a regional mesh that will smooth high-frequency artifacts and (2) a second interpolation that preserves the detailed information measured along the profiles. The challenge, especially for SP interpolation maps, is to preserve the high-amplitude and shortwavelength SP anomalies. Indeed, these can be interpreted in terms of structural limits (e.g., fault systems), which is one of the key applications of the SP method (Finizola et al., 2002, 2003, 2009; Bennati et al., 2011). Basically, field data are used to produce a grid with large spacing (e.g., 10 times the minimum spacing of the field data, e.g., $200 \mathrm{~m}$ for a field data acquisition spacing of $20 \mathrm{~m}$ ). From this grid, a new series of data is extracted by converting the grid to an ASCII XYZ file, which can be edited in a spreadsheet program. The data must be combined with the original field data in a unique spreadsheet. This new data set created has a more even distribution of the data points in the whole study area and preserves the high resolution of the data along the SP profiles. It can

field and grid data be used to perform a second interpolation/gridding, but this time with smaller grid spacing (usually two times the spacing used along the SP profiles $=40 \mathrm{~m}$ ). The resulting grid can be used to create the final SP map. The aim when creating a mesh of approximately 10 times the measurement step is to create a smoothed grid between the SP profiles before the final interpolation (Finizola et al., 2002). Obviously, in interpolation, one can always make different choices for algorithms. However, our key message here is to take a widely adopted interpolation algorithm (kriging) implemented in many commercial software packages and demonstrate the benefits of using our double-gridding method in addi-
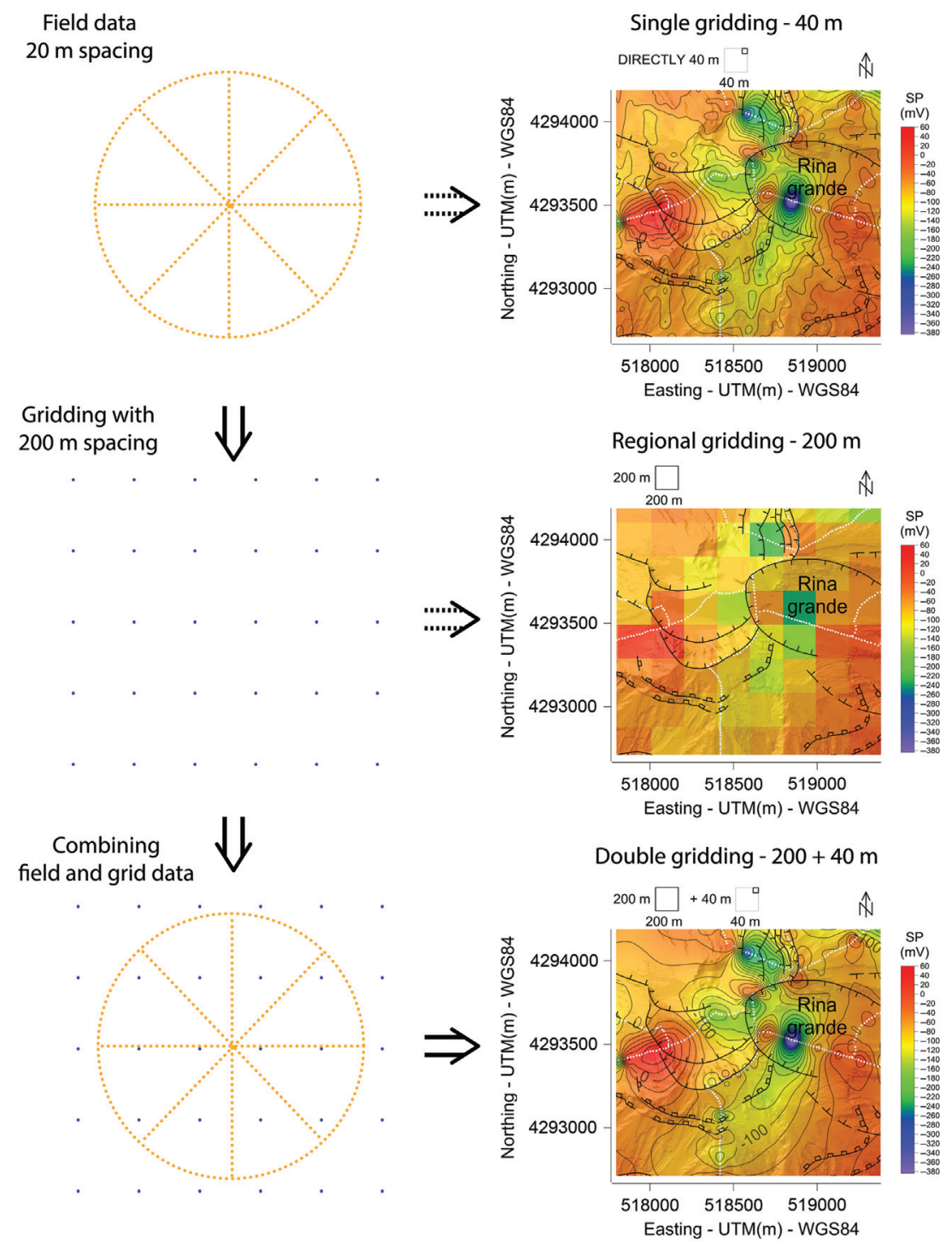

Figure 10. Double interpolation/gridding of the SP data for an irregular distri bution of the measurement points in the field. Step 1 creates a grid with a large spacing $(200 \mathrm{~m})$. The resulting data are added to the original data in step 2 to finally create a grid with spacing corresponding to two times the measurement spacing along individual profiles $(40 \mathrm{~m})$. The white dots represent the $\mathrm{SP}$ meas urement points. SP maps are extracted from the Stromboli SP map (modified from Finizola et al. [2002]; see the whole map in Figure 11 with details of the differences and benefits of the double gridding at a greater scale). 
tion to kriging. Here, the two gridding steps are performed with the kriging method, which is also a good option to interpolate unevenly sampled data. Combined with the double-gridding approach, the results show a faithful representation of the data close to the profiles and smoothed artifacts far from them. High and low filters, to filter out anomalous outliers, can also be used on the corrected SP data, to smooth the final result (Thanassoulas, 1989). A downside of this approach would be that the user has to define the upper and lower bounds of these filters, and it will be a bit arbitrary unless the user has clear physical reasons to select these specific values. Filtering also means that anomalously high or low SP values, even though they can be realistic, may be removed from the data.

Figure 11 is an example case study using SP data from Stromboli volcano. The general aspect of the map is relatively similar, but a rapid comparison of the two maps exemplifies the usefulness of a double-gridding process. Calculating a grid directly from the corrected SP data generates a high-frequency signal that can mislead scientific interpretation. Indeed, the appearance of short-wavelength SP anomalies in areas not well covered by field measurements can confuse the reader (e.g., the yellow anomaly in box 1 in Figure 11). Artifacts can sometimes be very close to actual data and look like large-scale anomalies (box 2 in Figure 11). This two-step procedure preserves the density of the data along the profiles and the position and extension of the real SP anomalies (e.g., box 3 in Figure 11). The general aspect of the map is greatly improved because most of the high-frequency artifacts are removed (e.g., box 4 in Figure 11) and the first-order information is revealed. However, even with an enhanced representation, it is important to remember that the interpretation of such maps should always be done keeping in mind the acquisition geometry. There are many different choices to make with respect to the interpolation. Our example demonstrates that different choices can improve the final results and interpretability of the data. One direction to explore, for example, is the addition of topography, or other prior information, as a cokriging property.

Once a basic map is created, several steps can be carried out to enhance it and highlight as much information as possible, such as blanking the map away from the data points (i.e., removing interpolated areas outside of the area of interest, where no data are available), or creating a custom color scale. This will not modify the information obtained from and represented by the data, but it will ease the perception of the first-order results in the map, and it will aid in the interpretation of SP data.

\section{SP versus distance graphs}

SP data can be presented as graphs/plots, showing $\mathrm{SP}$ values as a function of the distance along a profile, or as a function of the altitude. As a function of the distance, graphs can be used to precisely localize, for example, anomalies of the SP signal related to structural discontinuities of the ground, such as faults and fissures (Finizola et al., 2002; Bennati et al., 2011), to delineate hydrothermally active zones (e.g., the typical W-shaped SP signal on volcanoes) (Ishido, 2004; Gonzales et al., 2014), or to define the spatial extent of preferential
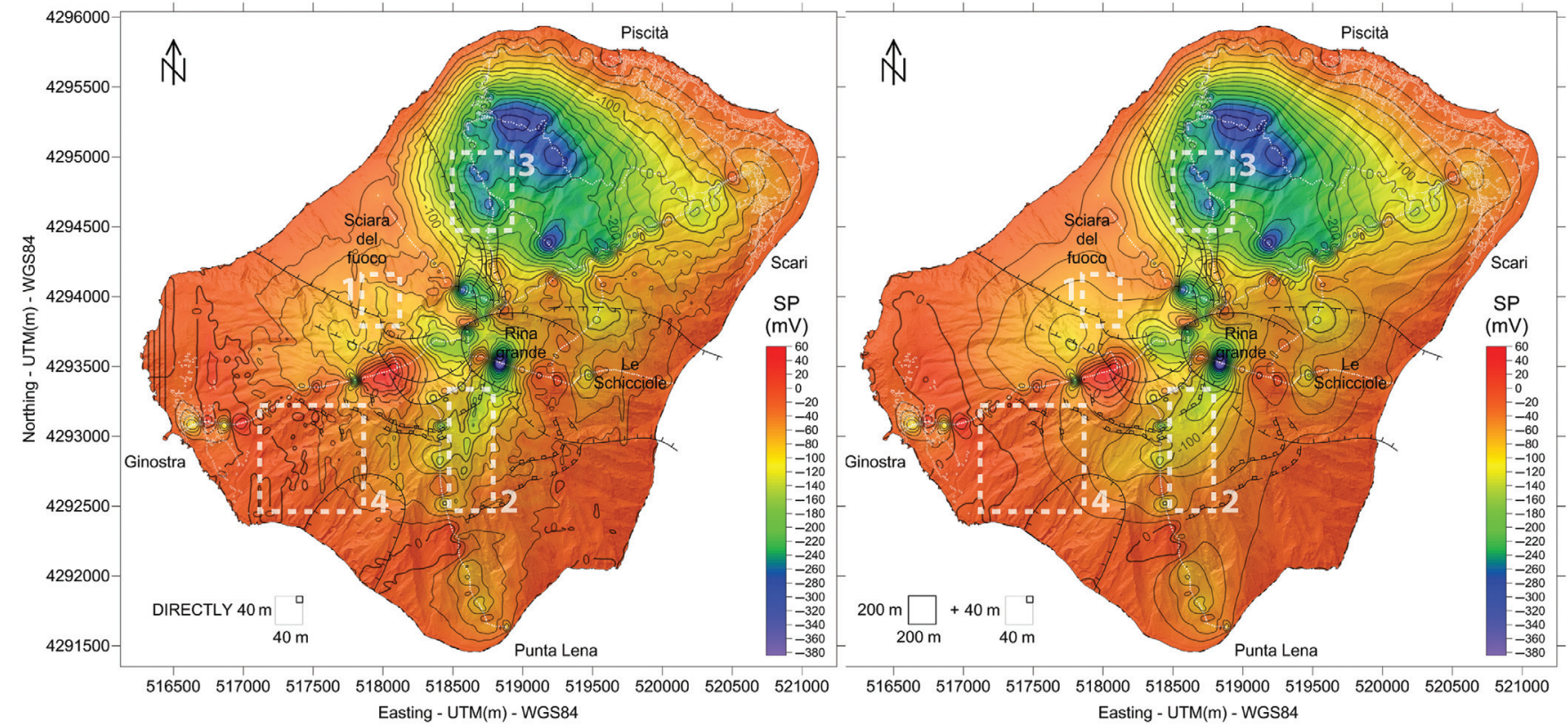

Figure 11. Study case example of a single gridding, directly to a $40 \mathrm{~m}$ resolution (the left side) compared with a double gridding with interpolation at 200 and $40 \mathrm{~m}$ (the right side) of SP data from Stromboli (modified from Finizola et al., 2002). The white dots represent the SP measurement points. The dashed boxes show artifacts that are being removed (boxes 1,2, and 4) without altering the resolution and accuracy of the map in areas well covered by the measurements in the field (box 3). The maps in Figure 10 show the central part of the present figure. 
groundwater flow pathways (Revil et al., 2005). This is where the effort of acquiring data with short measurement spacing really pays off. Studies with $1 \mathrm{~m}$ measurement spacing (Finizola et al., 2009), although time consuming, enable us to locate structural discontinuities in great detail and allow for assessing potential limits of collapses associated with preexisting or incipient fault planes (Barde-Cabusson et al., 2012; Chaput et al., 2019).

In the Garrotxa, a dormant monogenetic volcanic field located in northern Spain, the Rocanegra (RN) and Puig Subià (PS) volcanic cones are thought to be built on the same north-northeast-south-southwest eruptive fissure (Barde-Cabusson et al., 2014). They are two well-preserved volcanic edifices aligned along a north-northeast-south-southwest direction that is also reflected by gravimetry data acquired at the same study site. In the alignment of those two volcanic edifices, the authors identified a clear SP minimum on one SP profile intersecting the fissure (Figure 12b, profile $a-b$; the fissure is represented as the dashed orange line). Profile $a-b$ crosses the fissure in a rough southwest-northeast direction, and, even if the signal is noisy, it clearly highlights the area affected by the fissure. Usually, an SP anomaly associated with a fault would rather show up as a narrow peak in the SP data, but in this case, the ground may be fractured over a broader area due to past volcanic or tectonic activity. The northern half of profile c-d follows a path nearly parallel to the alignment of RN and PS volcanic cones, and then it shows decreasing SP values when approaching the eruptive fissure. This SP profile shows a $150 \mathrm{mV}$ minimum, well-defined by at least 35 measurement points, and interpreted as being associated to the eruptive fissure (Barde-Cabusson et al., 2014). However, in this latter case, nothing confirms that profile c-d actually crosses the eruptive fissure and the SP minimum observed can be called a "relative minimum," that is, relative to the rest of the data in this profile. This minimum indicates that the profile passes close to the eruptive fissure and, in a case in which no other data would support the location of the fissure, the information could be used to plan follow-up data acquisition. This is an important discussion for the interpretation of SP profiles because (1) we define "real" and "relative" minima that, respectively, correspond to the actual intersection of an SP profile with a fault or fissure, or to an anomaly in the vicinity of this structural limit and (2) we highlight the fact that getting results of other geophysical or geochemical methods available at the same location can substantially help the interpretation of such SP plots, and in any case, knowledge of the general geology of the study area is a prerequisite for any attempt at interpreting an SP profile. We also want to emphasize that for SP versus distance graphs, the shorter the measurement spacing, the better the SP data can detect small-scale structures.

\section{$S P$ versus elevation graphs}

The effect of the elevation variations or the so-called topographic effect (e.g., Zlotnicki and Nishida, 2003) involves a constant linear SP/elevation relationship (e.g., Lénat, 2007) explained by a water table whose depth increases regularly with elevation in a homogeneous medium. In the W-shapes signal observed on active volcanoes, the external branches of the "W" are then explained as the decrease of the signal while climbing the slopes of the volcano. SP versus elevation graphs can be built using the whole SP data set of the study area and the elevation information at the same measurement points. It is useful in a hydrogeologic context as well as in areas showing hydrothermal activity, to delineate different hydrogeologic and hydrothermal domains. A simple approach consists of representing the $\mathrm{SP}$ versus elevation data in a graph. The strategy here is to identify and extract SP values and the corresponding elevation of the measurements from different key areas of the study site. Those key areas are delimited by a general knowledge of the geologic and structural features of the study site or, more interestingly, the SP versus elevation plot itself will help in identifying different groups of data corresponding to, for example, areas with different hydrogeologic characteristics. Figure 13 shows two examples on the active Piton de la Fournaise volcanic cone (Réunion Island, France; Barde-Cabusson et al., 2012) and dormant Garrotxa monogenetic field (Catalonia, Spain; Barde-Cabusson et al., 2014). On the active Piton de la Fournaise area, which is a hydrothermal context, different groups of the SP versus elevation data are clearly identified because they show
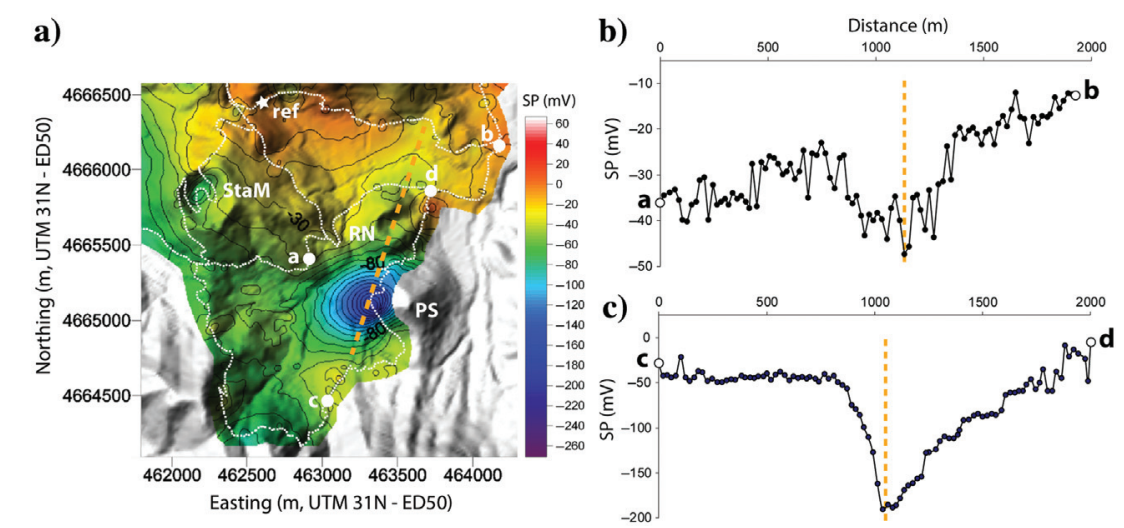

Figure 12. (a) Section of the SP map acquired in Garrotxa (Catalonia, Spain). (b and c) SP versus distance graphs along selected SP profiles (a b and c d). StaM, RN, and PS stand for the Santa Margarida, Rocanegra, and Puig Subià volcanoes, respectively, and ref is the reference for the SP data set. The dashed orange line is the eruptive fissure between RN and PS, and the small white dots are the SP measurements. Profile a b defines a real SP minimum, whereas $c d$ shows a rel ative SP minimum (see the text for an explanation; [a and b] has been modified from Barde Cabusson et al., 2014). 
a)
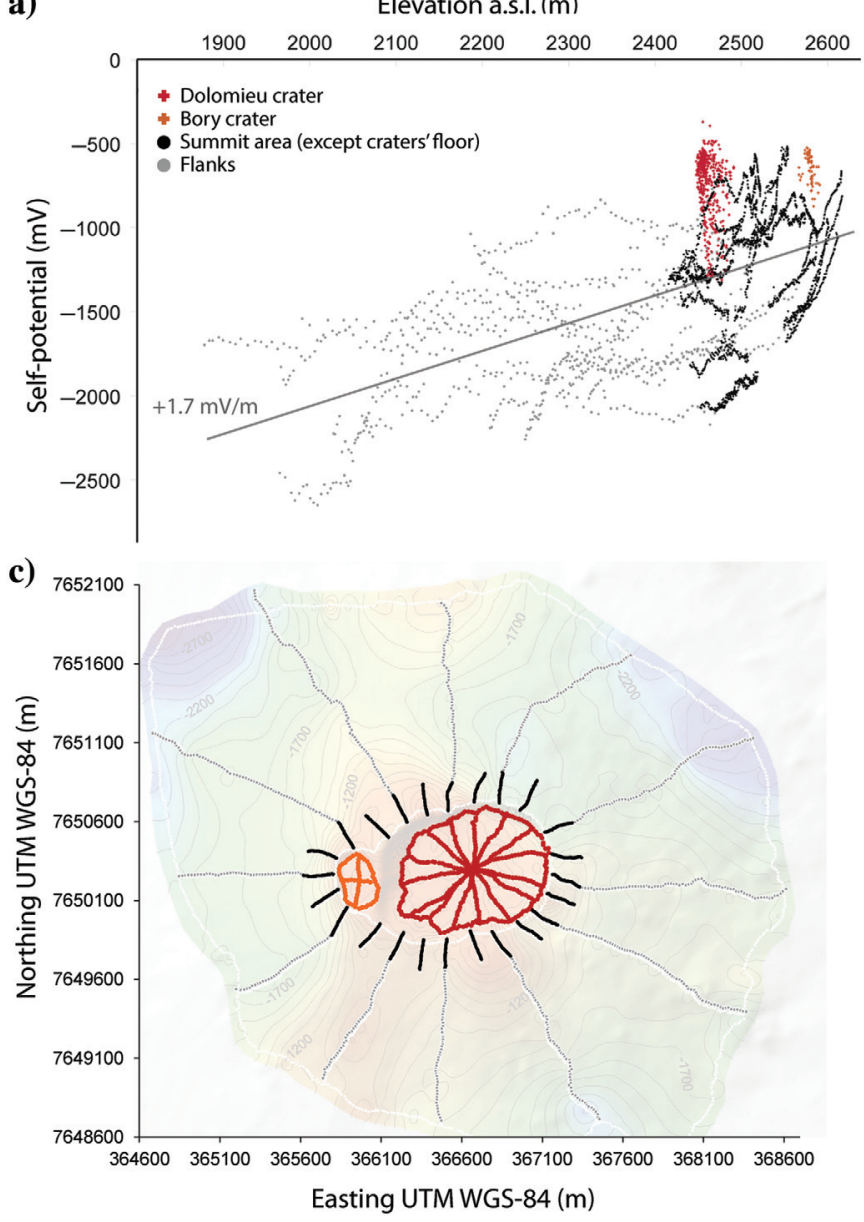

b)
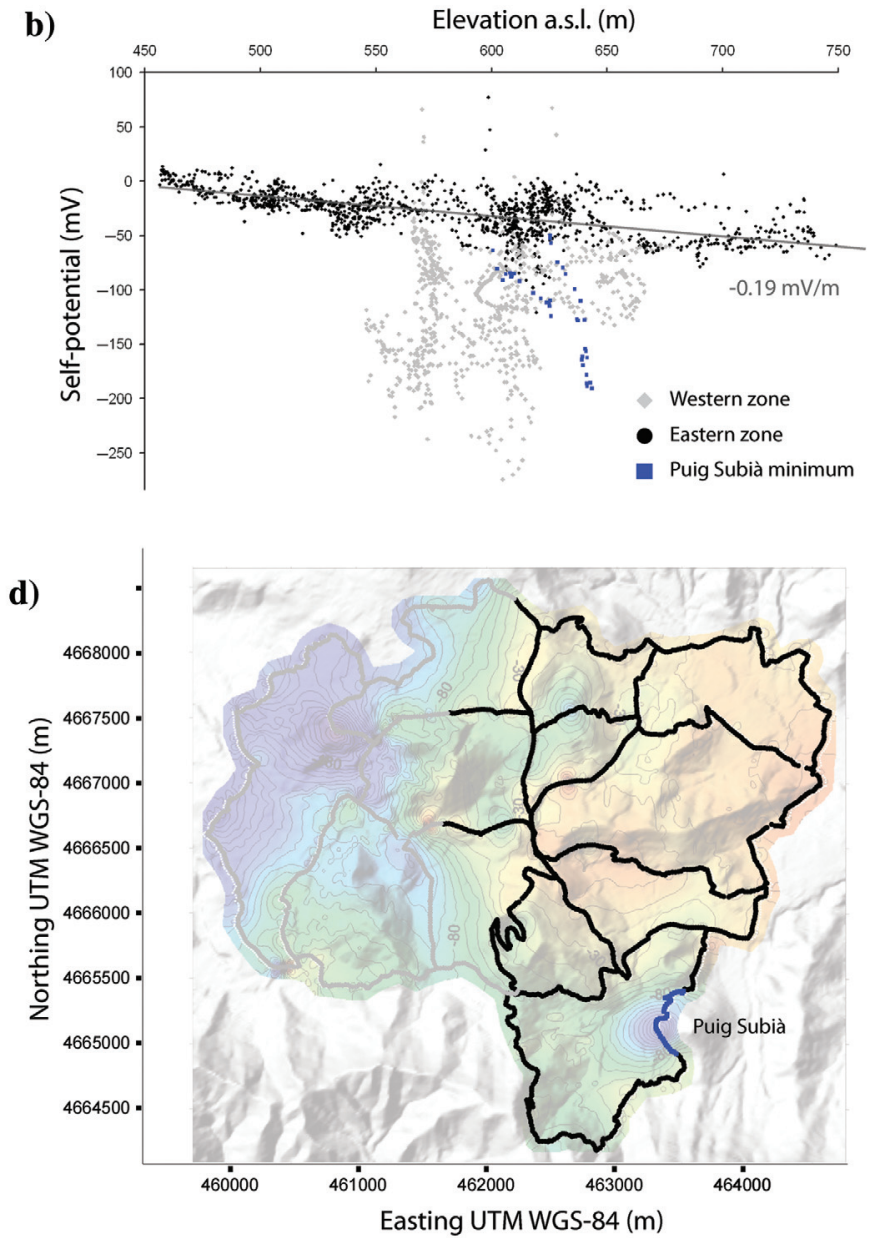

Figure 13. ( $a$ and $b$ ) The SP versus elevation graphs of the Piton de la Fournaise cone (Réunion Island, France) and Garrotxa (Catalonia, Spain), respectively. (c and d) The data points displayed on the corresponding SP map and digital elevation map. The colors of the data points in the corresponding graphs and maps (a and $c$, and b and d) are the same ([a and c] are modified from Barde Cabusson et al., 2012; [b and d] are modified from Barde Cabusson et al., 2014).

different trends. Those groups correspond to different intensities of the hydrothermal activity likely due to more (nearly vertical trend) or less (flatter trend) intense hydrothermal flow. Low hydrothermal activity on the flanks of the cone is characterized by a $+1.7 \mathrm{mV} / \mathrm{m}$ gradient (corresponding to the slope of the linear regression of this group; Figure 13a). The summit area shows a different trend with a greater general slope, and the two summit craters show a nearly vertical trend associated to an intense hydrothermal activity. In the Garrotxa volcanic zone (Barde-Cabusson et al., 2014), two major groups of data were identified with an eastern zone (the black data points in Figure 13b) showing a $-0.19 \mathrm{mV} / \mathrm{m}$ trend characteristic of hydrogeologic zones (Lénat, 2007). A western group (the gray data points in Figure 13b) shows more chaotic behavior. Some local anomalies, such as the high infiltration along the Puig Subià eruptive fissure, can contrast with the main trend (the blue data points in Figure 13b). The two zones are interpreted to be areas with different hydrogeologic contexts (Barde-Cabusson et al., 2014). Going further in the processing of SP versus elevation data, Lénat (2007) shows that computing the SP/elevation gradient is useful for qualitative interpretation of SP data; the author shows that the gradient is more sensitive to variations of the SP signal associated to the presence of perched aquifers, to lateral variations of underground physical properties, or to upward hydrothermal circulations of fluids.

\section{Conclusion}

The SP method is a simple method whether regarding the acquisition of the measurements in the field, or the processing of the data. However, the reference and the closure corrections of SP data are vital to SP processing and the significance of a good planning of SP acquisition in view of applying those corrections, that is, in particular that the prepared plan must include closed profiles (loops) interconnected to common measurement points in the field for the purpose of applying the closure correction. The reference correction allows us to connect different sections of a profile, whereas the closure correction allows us to correct the drift of SP measurements and sets a unique refer- 
ence for the whole data set. This is an essential condition to visualize the result on a map. We show that data acquisition spacing is a critical parameter that will determine the size of the geologic and structural features that we will be able to identify. Acquiring data with small spacing along the survey lines (or profiles), even if the profiles are distant from each other, will give an opportunity to interpret the data with a great amount of detail. Although SP versus distance graphs can locate structural limits precisely, maps and SP versus elevation graphs identify hydrogeologic or hydrothermal domains of different intensities at a greater scale. A preliminary step consisting of double gridding the corrected data set is not a compulsory step, but it has shown to be useful to counteract the effects of an uneven distribution of the measurements in the field in addition to the use of a method such as kriging. Using both allows us to keep detailed information close to the data points and to smooth artifacts far from it. SP maps will highlight first-order information and can help to identify key areas for continued studies (using SP and/or other geophysical methods and data types).

The robust practical data acquisition and processing method that is proposed here will help several researchers across many disciplines to plan their SP surveys, acquire good-quality data, get reliable results with the method through an efficient processing, visualize the data, and, finally, interpret the results for their own fields of research.

\section{Acknowledgments}

We want to thank the members of the team led by A. Finizola in the Aeolian Islands, who participated in data acquisition, some of which is unpublished, and particularly for the data acquisition resulting in the SP map of Stromboli that is used in this paper to demonstrate the two-step interpolation of SP maps. In the same way, we are grateful to the numerous individuals who contributed to data acquisition on Piton de la Fournaise and at the Garrotxa volcanic field for the great teamwork in acquiring the data used to illustrate some of the examples in this paper. The authors would like to thank M. Aubert, J.-F. Lénat, A. Revil, E. Delcher, and the works performed in collaboration with STRATAGEM974, for very interesting discussions over several years. We thank the associate editor of Interpretation V. Egorov and our reviewers P. Wolfgram, M. Pezzoli, M. Saribudak, K. Titov, and an anonymous reviewer for reviews that truly improved the final version of this manuscript.

This is contributed paper \#2434 of the Hawai'i Institute of Geophysics and Planetology, \#11171 of the School of Ocean and Earth Science and Technology, and WRRC-CP-2021-06 of the Water Resources Research Center, University of Hawai'i at Mānoa, Honolulu, Hawai‘i, USA.

S. Barde-Cabusson is currently $100 \%$ funded by the National Science Foundation's Established Program to Stimulate Competitive Research (NSF EPSCoR) 'Ike Wai project, and N. Grobbe is funded for $50 \%$ by the NSF EPSCoR 'Ike Wai project and $50 \%$ by the University of Hawai'i at the Mānoa Water Resources Research Center. Support for the Hawai'i EPSCoR Program is provided by the National Science Foundation's Research Infrastructure Improvement (RII) Track-1: 'Ike Wai: Securing Hawaii's Water Future Award \# OIA-1557349.

This study contributes to the IdEx Université de Paris ANR-18-IDEX-0001. The work of A. Finizola is IPGP contribution \#4141.

\section{Data and materials availability}

Confirm that the manuscript has been submitted solely to this journal and is not published, in press, or submitted elsewhere.

\section{References}

Aizawa, K., 2008, Classification of self-potential anomalies on volcanoes and possible interpretations for their subsurface structure: Journal of Volcanology and Geothermal Research, 175, 253 268, doi: 10.1016/j.jvolgeores .2008.03.011.

Anderson, L. A., and G. R. Johnson, 1973, Application of the self-potential method in the exploration for geothermal energy in Long Valley, California: Eos, Transactions American Geophysical Union, 54, 1212.

Anderson, L. A., and G. R. Johnson, 1976, Application of the self-potential method to geothermal exploration in Long Valley, California: Journal of Geophysical Research, 81, 1527 1532, doi: 10.1029/JB081i008p01527.

Anderson, L. A., and G. R. Johnson, 1979, Some observations of the self-potential effect in geothermal areas in Hawaii and Nevada: Geothermal Resources Council, Transactions, 2, 912.

Aubert, M., and Y. Q. Atangana, 1996, Self potential-method in hydrogeological exploration of volcanic areas: Ground Water, 34, 1010 1016, doi: 10.1111/j.1745-6584 .1996.tb02166.x.

Ballestracci, R., 1982, Self-potential survey near the craters of Stromboli volcano (Italy). Inference for internal structure and eruption mechanism: Bulletin of Volcanology, 45, 349 365, doi: 10.1007/BF02597257.

Banwell, C. J., 1970, Geophysical techniques in geothermal exploration: UN Symposium on the Development and Utilization of Geothermal Resources 1, 32.

Barde-Cabusson, S., 2007, Formation de caldera par fluage d'un système hydrothermal volcanique (in French): Ph.D. thesis, Université Blaise Pascal, Clermont-Ferrand (France), 203.

Barde-Cabusson, S., A. Finizola, A. Peltier, M. Chaput, N. Taquet, S. Dumont, Z. Duputel, A. Guy, L. Mathieu, S. Saumet, F. Sorbadère, and M. Vieille, 2012, Structural control of collapse events inferred by self-potential mapping on the Piton de la Fournaise volcano (La Réunion Island): Journal of Volcanology and Geothermal Research, 209-210, 9 18, doi: 10.1016/j.jvolgeores.2011 .09 .014 . 
Barde-Cabusson, S., A. Finizola, A. Revil, T. Ricci, S. Piscitelli, E. Rizzo, B. Angeletti, M. Balasco, L. Bennati, S. Byrdina, N. Carzaniga, A. Crespy, F. Di Gangi, J. Morin, A. Perrone, M. Rossi, E. Roulleau, B. Suski, and N. Villeneuve, 2009, New geological insights and structural control on fluid circulation in La Fossa cone (Vulcano, Aeolian Islands, Italy): Journal of Volcanology and Geothermal Research, 185, 231 245, doi: 10.1016/j .jvolgeores.2009.06.002.

Barde-Cabusson, S., J. Gottsman, J. Martí, X. Bolós, A. G. Camacho, A. Geyer, L. L. Planagumà, E. Ronchin, and A. Sanchez, 2014, Structural control of monogenetic volcanism in the Garrotxa volcanic field (Northeastern Spain) from gravity and self-potential measurements: Bulletin of Volcanology, 76, 788, doi: 10.1007/s00445013-0788-0.

Barus, C., 1882, On the electrical activity of ore bodies. Geology of the Comstock lode and the Washoe District: U.S. Geological Survey, Monographs of the United States Geological Survey, 309367.

Bennati, L., A. Finizola, J. Walker, D. Lopez, C. HiguieraDiaz, C. Schütze, F. Barahona, R. Cartagena, V. Conde, R. Funes, and C. Rios, 2011, Fluid circulation in a complex volcano-tectonic setting, inferred from self-potential and soil CO2 flux surveys: The Santa María Cerro Quemado Zunil volcanoes and Xela caldera (northwestern Guatemala): Journal of Volcanology and Geothermal Research, 199, 216 229, doi: 10.1016/ j.jvolgeores.2010.11.008.

Biswas, A., 2017, A review on modeling, inversion and interpretation of self-potential in mineral exploration and tracing paleo-shear zones: Ore Geology Reviews, 91, 21 56, doi: 10.1016/j.oregeorev.2017.10.024.

Blanchard, D. C., 1964, Charge separation from saline drops on hot surfaces: Nature, 201, 11641166.

Bolève, A., F. Janod, A. Revil, A. Lafon, and J.-J. Fry, 2011, Localization and quantification of leakages in dams using time-lapse self-potential measurements associated with salt tracer injection: Journal of Hydrology, 403, 242 252, doi: 10.1016/j.jhydrol.2011.04.008.

Bolós, X., S. Barde-Cabusson, D. Pedrazzi, J. Martí, A. Casas, M. Himi, and R. Lovera, 2012, Investigation of the inner structure of La Crosa de Sant Dalmaimaar (Catalan Volcanic Zone, Spain): Journal of Volcanology and Geothermal Research, 247-248, 37 48, doi: 10.1016/j .jvolgeores.2012.08.003.

Bolós, X., G. Cifuentes, J. L. Macías, G. Sosa-Ceballos, F. Garcia-Tenorio, and M. Albor, 2019, Geophysical imaging of fluid circulation and its relation with the structural system of Cerritos Colorados geothermal field, La Primavera caldera (Mexico): Journal of Volcanology and Geothermal Research, 369, 238 249, doi: 10.1016/j .jvolgeores.2018.11.015.

Boudoire, G., A. Finizola, A. Di Muro, A. Peltier, M. Liuzzo, F. Grassa, E. Delcher, C. Brunet, P. Boissier, M. Chaput, V. Ferrazzini, and S. Gurrieri, 2018, Small-scale spatial variability of soil CO2 flux: Implication for monitoring strategy: Journal of Volcanology and Geothermal Research, 366, 13 26, doi: 10.1016/j.jvolgeores.2018.10 .001 .

Brothelande, E., A. Finizola, A. Peltier, E. Delcher, J.-C. Komorowski, F. Di Gangi, G. Borgogno, M. Passarella, C. Trovato, and Y. Legendre, 2014, Fluid circulation pattern inside La Soufrière volcano (Guadeloupe) inferred from combined electrical resistivity tomography, selfpotential, soil temperature and diffuse degassing measurements: Journal of Volcanology and Geothermal Research, 288, 105 122, doi: 10.1016/j.jvolgeores.2014 .10.007.

Castermant, J., C. A. Mendonça, A. Revil, F. Trolard, G. Bourrié, and N. Linde, 2008, Redox potential distribution inferred from self potential measurements during the corrosion of a burden metallic body: Geophysical Prospecting, 56, 269 282, doi: 10.1111/j.1365-2478 .2007.00675.x.

Chaput, M., A. Finizola, A. Peltier, N. Villeneuve, M. Crovisier, and S. Barde-Cabusson, 2019, Where does a volcano break? Using self-potential reiteration in forecasting the precise location of major destructive events on active volcanoes: The case study of the Piton de la Fournaise 2007 caldera collapse: Volcanica, 2, 151 159, doi: 10.30909/vol.02.02.151159.

Corwin, R. F., 1973, Offshore application of self-potential prospecting: Ph.D. thesis, University of California, 303.

Corwin, R. F., 1975, Use of the self-potential method for geothermal exploration: U.S. Energy Research and Development Administration Report, Technical information division, Lawrence Berkeley Laboratory, University of California, 53.

Corwin, R. F., 1976, Self-potential exploration for geothermal reservoirs: Proceedings of the 43rd Workshop on Geothermal Reservoir Engineering, U.S. Government Printing Office, Washington, D.C. 2, 937945.

Corwin, R. F., and D. B. Hoover, 1979, The self-potential method in geothermal exploration: Geophysics, 44, 226 245, doi: 10.1190/1.1440964.

Dessau, G., 1950, Some results of geophysical prospecting conducted for the Geological Survey of India from 19451948: Geophysics, 15, 704 731, doi: 10.1190/1.1437635.

Dickey, P. A., 1944, Natural potentials in sedimentary rocks: Transactions of the AIME, 155, 39 48, doi: 10.2118/ 944039-G.

Doussan, C., L. Jouniaux, and J.-L. Thony, 2002, Variations of self-potential and unsaturated water flow with time in sandy loam and clay loam soils: Journal of Hydrology, 267, 173 185, doi: 10.1016/S0022-1694(02)00148-8.

Eppelbaum, L. V., 2019, Advanced analysis of self-potential data in ore deposits of the South Caucasus: ANAS Transactions, Earth Sciences, 2, 21 35, doi: 10.33677/ ggianas20190200029.

Finizola, A., 2017, Approche pluridisciplinaire des circulations de fluides au sein de volcans actifs: Habilitation à 
diriger des recherché (in French): Ph.D. thesis, Université de La Réunion (France), 378.

Finizola, A., M. Aubert, A. Revil, C. Schütze, and F. Sortino, 2009, Importance of structural history in the summit area of Stromboli during the 2002-2003 eruptive crisis inferred from temperature, soil $\mathrm{CO} 2$, self-potential, and electrical resistivity tomography: Journal of Volcanology and Geothermal Research, 183, 213 227, doi: 10 .1016/j.jvolgeores.2009.04.002.

Finizola, A., J.-F. Lénat, O. Macedo, D. Ramos, J.-C. Thouret, and F. Sortino, 2004, Fluid circulation and structural discontinuities inside Misti volcano (Peru) inferred from self-potential measurements: Journal of Volcanology and Geothermal Research, 135, 343 360, doi: 10.1016/j.jvolgeores.2004.03.009.

Finizola, A., F. Sortino, J.-F. Lénat, M. Aubert, M. Ripepe, and M. Valenza, 2003, The summit hydrothermal system of Stromboli. New insights from self-potential, temperature, CO2 and fumarolic fluid measurements, with structural and monitoring implications: Bulletin of Volcanology, 65, 486 504, doi: 10.1007/s00445-0030276-z.

Finizola, A., F. Sortino, J.-F. Lénat, and M. Valenza, 2002, Fluid circulation at Stromboli volcano (Aeolian Islands, Italy) from self-potential and soil gas surveys: Journal of Volcanology and Geothermal Research, 116, 1 18, doi: 10.1016/S0377-0273(01)00327-4.

Fournier, C., 1989, Spontaneous potentials and resistivity surveys applied to hydrogeology in a volcanic area: Case history of the chaîne des Puys (Puy de Dôme, France): Geophysical Prospecting, 37, 647 668, doi: 10.1111/j.1365-2478.1989.tb02228.x.

Fox, R. W., 1830, XXV. On the electro-magnetic properties of metalliferous veins in the mines of Cornwall: Philosophical Transactions of the Royal Society of London, 120, 399 414, doi: 10.1098/rstl.1830.0027.

Gay, S. P., Jr., 1967, A 1,800 millivolt self-potential anomaly near Hualgayoc, Peru: Geophysical Prospecting, 15, 236 245, doi: 10.1111/j.1365-2478.1967.tb01786.x.

Gex, P., 1977, La Méthode de polarisation spontanée, essai de réhabilitation: Ph.D. Thèse, Université de Lausanne (Switzerland), 97.

Gex, P., 1980, Phénomènes d'électrofiltration liés à quelques sites de barrages: Bulletin de la Société Vaudoise des Sciences Naturelles, 75, 3950.

Gonzales, K., A. Finizola, J.-F. Lénat, O. Macedo, D. Ramos, J.-C. Thouret, N. Fournier, V. Cruz, and K. Pistre, 2014, Asymmetrical structure, hydrothermal system and edifice stability: The case of Ubinas volcano, Peru, revealed by geophysical surveys: Journal of Volcanology and Geothermal Research, 276, 132 144, doi: 10.1016/j .jvolgeores.2014.02.020.

Gorsich, D. J., and M. G. Genton, 2000, Variogram model selection via nonparametric derivative estimation: Mathematical Geology, 32, 249 270, doi: 10.1023/A: 1007563809463.
Grobbe, N., and S. Barde-Cabusson, 2019, Self-potential studies in volcanic environments: A cheap and efficient method for multiscale fluid-flow investigations: International Journal of Geophysics, 2019, 1 19, doi: 10.1155/ 2019/2985824.

Halbwachs, M., 1983, Electrical and electromagnetic methods, Chapître 34 in forecasting volcanic events, in $\mathrm{H}$. Tazieff and J.-C. Sabroux, eds., Developments in volcanology 1: Elsevier, 507528.

Hase, H., T. Hashimoto, S. Sakanaka, W. Kanda, and Y. Tanaka, 2005, Hydrothermal system beneath Aso volcano as inferred from self-potential mapping and resistivity structure: Journal of Volcanology and Geothermal Research, 143, 259 277, doi: 10.1016/j.jvolgeores.2004.12 .005 .

Henriet, J. P., 1971, Large self-potential anomalies in the Noir Ri basin (Ardennes, Belgium): Bulletin de la Société Belge de Géologie, de Paléontologie et d'hydrologie, 80, 8596.

Ishido, T., 2004, Electrokinetic mechanism for the "W"-shaped self-potential profile on volcanoes: Geophysical Research Letters, 31, L15616, doi: 10.1029/ 2004GL020409.

Ishido, T., Y. Nishi, and J. W. Pritchett, 2010, Application of self-potential measurements to geothermal reservoir engineering: Characterization of fractured reservoirs: 35th Workshop on Geothermal Reservoir Engineering, Stanford University, SGP-TR-188.

Jardani, A., A. Revil, F. Akoa, M. Schmutz, N. Florsch, and J. P. Dupont, 2006, Least squares inversion of self-potential (SP) data and application to the shallow flow of ground water in sinkholes: Geophysical Research Letters, 33, L19306, doi: 10.1029/ 2006 GL027458.

Jardani, A., A. Revil, W. Barrash, A. Crespy, E. Rizzo, S. Straface, M. Cardiff, B. Malama, C. Miller, and T. Johnson, 2009, Reconstruction of the water table from selfpotential data: A Bayesian approach: Groundwater, 47, 213 227, doi: 10.1111/j.1745-6584.2008.00513.x.

Johnston, M. J. S., J. D. Byerlee, and D. Lockner, 2001, Rapid fluid disruption: a source of selfpotential anomalies on volcanoes: Journal of Geophysical Research, 106, 43274335.

Jouniaux, L., A. Maineult, V. Naudet, M. Pessel, and P. Sailhac, 2009, Review of self-potential methods in hydrogeophysics: Comptes Rendus Géoscience, 341, 928 936, doi: 10.1016/j.crte.2009.08.008.

Kruger, F. C., and W. C. Lacy, 1949, Geological explanation of geophysical anomalies near Cerro de Pasco, Peru: Economic Geology, 44, 485 491, doi: 10.2113/gsecongeo. 44.6.485.

Kulessa, B., B. Hubbard, and G. H. Brown, 2003, Crosscoupled flow modeling of coincident streaming and electrochemical potentials and application to subglacial self-potential data: Journal of Geophysical Research, 108, 2381, doi: 10.1029/2001JB001167. 
Lénat, J.-F., 1987, Structure et dynamique interne d'un volcan basaltique intraplaque océanique: Le Piton de la Fournaise (île de la Réunion): Thèse d'Etat, Univ. Blaise Pascal, Clermont-Ferrand (France), 337.

Lénat, J.-F., 2007, Retrieving self-potential anomalies in a complex volcanic environment: An SP/elevation gradient approach: Near Surface Geophysics, 5, 161 170, doi: 10.3997/1873-0604.2006028.

Lénat, J.-F., M. Aubert, and C. Archambault, 1982, Relations spatiales et temporelles de la polarisation spontanée (P.S.) et des températures à l'Etna. Perspectives de la méthode P.S. en tant que méthode de surveillance: 9ème Réunion Annuelle des Sciences de la Terre, Paris (Soc. géol. Fr. ed.), 376.

Leroy, P., and A. Revil, 2004, A triple-layer model of the surface electrochemical properties of clay minerals: Journal of Colloid and Interface Science, 270, 371 380, doi: 10.1016/j.jcis.2003.08.007.

Leuangthong, O., and C. V. Deutsch, 2004, Transformation of residuals to avoid artifacts in geostatistical modelling with a trend: Mathematical Geology, 36, 287 305, doi: 10.1023/B:MATG.0000028438.48852.b0.

Linde, N., and A. Revil, 2007, Inverting self potential data for redox potentials of contaminant plumes: Geophysical Research Letters, 34, doi: 10.1029/ 2007 GL030084.

Lowrie, W., 2007, Fundamentals of geophysics, 2nd ed.: Cambridge University Press.

McClean, C. J., and I. S. Evans, 2000, Apparent fractal dimensions from continental scale digital elevation models using variogram methods: Transactions in GIS, 4, 361 378, doi: 10.1111/1467-9671.00061.

Minsley, B. J., 1997, Modeling and inversion of self-potential data: B.S. Applied Physics, Purdue University.

Mounce, W. D., and W. M. Rust, 1945, Natural potentials in well logging: Transactions of the AIME, 164, 288294.

Neufeld, C. T., and B. J. Wilde, 2005, A global Kriging program for artifact-free maps: Centre for Computational Geostatistics, Report 7, University of Alberta, 403-1 401-8.

Nourbehecht, B., 1963, Irreversible thermodynamic effects in inhomogeneous media and their applications in certain geoelectric problems: Ph.D. thesis, Massachusetts Institute of Technology.

Nyquist, J. E., and C. E. Corry, 2002, Self-potential: The ugly duckling of environmental geophysics: The Leading Edge, 21, 446 451, doi: 10.1190/1.1481251.

Parasnis, D. S., 1973, Mining geophysics: Elsevier, 394.

Perrier, F. E., G. Petiau, G. Clerc, V. Bogorodsky, E. Erkul, L. Jouniaux, D. Lesmes, J. Macnae, J. M. Meunier, D. Morgan, D. Nascimento, G. Oettinger, G. Schwarz, H. Toh, M. J. Valiant, K. Vozoff, and O. Yazici-Cakin, 1997, A one-year systematic study of electrodes for long period measurements of the electric field in geophysical environments: Journal of Geomagnetism and Geoelectricity, 49, 1677 1696, doi: 10.5636/jgg.49.1677.
Petiau, G., 2000, Second generation of lead-lead chloride electrodes for geophysical applications: Pure and Applied Geophysics, 157, 357 382, doi: 10.1007/ s000240050004.

Pyrcz, M. J., and C. V. Deutsch, 2001, Two artifacts of probability field simulation: Mathematical Geology, 33, 775 799, doi: 10.1023/A:1010993113807.

Rao, M. R., 1943, Spontaneous polarization surveys near Guddadarangavvanahalli, Chitaldrug, Mysore State, India: Transactions of the AIME, 164, 107113.

Revil, A., 2002, Comment on "Rapid fluid disruption: A source for self-potential anomalies on volcanoes" by M. J. S. Johnston, J. D. Byerlee, and D. Lockner: Journal of Geophysical Research, 107, ETG 2-1 ETG 2-5, doi: 10 .1029/2001JB000788.

Revil, A., L. Cary, Q. Fan, A. Finizola, and F. Trolard, 2005, Self-potential signals associated with preferential ground water flow pathways in a buried paleo-channel: Geophysical Research Letters, 32, L07401, doi: 10.1029/ 2004 GL022124.

Revil, A., A. Finizola, S. Piscitelli, E. Rizzo, T. Ricci, A. Crespy, B. Angeletti, M. Balasco, S. Barde-Cabusson, L. Bennati, A. Bolève, S. Byrdina, N. Carzaniga, F. Di Gangi, J. Morin, A. Perrone, M. Rossi, E. Roulleau, and B. Suski, 2008, Inner structure of La Fossa di Vulcano (Vulcano Island, southern Tyrrhenian Sea, Italy) revealed by high-resolution electric resistivity tomography coupled with self-potential, temperature, and CO2 diffuse degassing measurements: Journal of Geophysical Research, 113, B07207, doi: 10.1029/ 2007JB005394.

Revil, A., A. Finizola, T. Ricci, E. Delcher, A. Peltier, S. Barde-Cabusson, G. Avard, T. Bailly, L. Bennati, S. Byrdina, J. Colonge, F. Di Gangi, G. Douillet, M. Lupi, J. Letort, and E. Tsang Hin Sun, 2011, Hydrogeology of Stromboli volcano, Aeolian Islands (Italy) from the interpretation of resistivity tomograms, self-potential, soil temperature, and soil CO2 concentration measurements: Geophysical Journal International, 186, 1078 1094, doi: 10.1111/j.1365-246X.2011.05112.x.

Revil, A., and A. Jardani, 2013, The self-potential method theory and applications in environmental geosciences, 1st ed.: Cambridge University Press, 383.

Revil, A., and P. A. Pezard, 1998, Streaming potential anomaly along faults in geothermal areas: Geophysical Research Letters, 25, 3197 3200, doi: 10.1029/ 98GL02384.

Saribudak, M., 2019, Surface geophysics, Edwards and Trinity aquifers, central Texas, in J. M. Sharp Jr., R. T. Green, and G. M. Schindel, eds., The Edwards aquifer, the past, present and future of a vital resource: Geological Society of America Memoir, 215.

Saribudak, M., and N. W. Hauwert, 2017, Integrated geophysical investigations of Main Barton Springs, Austin, Texas, USA: Journal of Applied Geophysics, 138, 114 126, doi: 10.1016/j.jappgeo.2017.01.004. 
Sato, M., and M. H. Mooney, 1960, The electrochemical mechanism of sulfide self-potentials: Geophysics, 25, 226 249, doi: 10.1190/1.1438689.

Schiavone, D., and R. Quarto, 1984, Self-potential prospecting in the study of water movements: Geoexploration, 22, 47 58, doi: 10.1016/0016-7142(84)90005-X.

Semenov, A. S., 1980, Electrical exploration: Natural polarization method (inRussian), 446.

Sheriff, R. E., 1978, A first course in geophysical exploration and interpretation (in German): International Human Resources Development Corporation, 313.

Sill, W. R., 1983, Self potential modeling from primary flows: Geophysics, 48, 76 86, doi: 10.1190/1.1441409.

Soudoplatoff, S., J.-F. Lénat, and J. P. Vilbonnet, 1982, Cartographie des anomalies thermiques du Piton de la Fournaise. Résultats obtenus par thermographie infrarouge et par cartographie de la polarisation spontanée (P.S.): 9ème Réunion Annuelle des Sciences de la Terre, Paris (Soc. géol. Fr. ed.), 583.

Suski, B., A. Revil, K. Titov, P. Konosavsky, M. Voltz, C. Dagès, and O. Huttel, 2006, Monitoring of an infiltration experiment using the self-potential method: Water Resources Research, 42, W08418, doi: 10.1029/2005WR004840.

Thanassoulas, C. P., 1989, Application of the self potential technique over the Milos geothermal test site: Geothermics, 18, 497 505, doi: 10.1016/0375-6505(89) 90052-7.

Van Ngoc, P., D. Boyer, and G. Kieffer, 1980, Sur l'existence d'une zone de forte conductivité électrique, en relation avec les éruptions sur le versant nord-est de l'Etna.
(Sicile): Comptes rendus de l'Académie des Sciences, 290D, 443446.

Villasante-Marcos, V., A. Finizola, R. Abella, S. BardeCabusson, M. J. Blanco, B. Brenes, V. Cabrera, B. Casas, P. De Agustin, F. Di Gangi, I. Dominguez, O. Garcia, A. Gomis, J. Guzman, I. Iribarren, G. Levieux, C. Lopez, N. Luengo-Oroz, I. Martin, M. Moreno, S. Meletlidis, J. Morin, D. Moure, J. Pereda, T. Ricci, E. Romero, C. Schütze, B. Suski-Ricci, P. Torres, and P. Trigo, 2014, Hydrothermal system of Central Tenerife volcanic complex, Canary Islands (Spain), inferred from self-potential measurements : Journal of Volcanology and Geothermal Research, 272, 59 77, doi: 10.1016/j.jvolgeores.2013.12.007.

Zablocki, C. J., 1976, Mapping thermal anomalies on an active volcano by the self-potential method, Kilauea, Hawaii: Proceedings of the 2nd U.N. Symposium of the development and use of geothermal resources 2, 12991309.

Zlotnicki, J., and Y. Nishida, 2003, Review on morphological insights of self-potential anomalies on volcanoes: Surveys in Geophysics, 24, 291 338, doi: 10.1023/B: GEOP.0000004188.67923.ac.

Zohdy, A. A. R., L. A. Anderson, and L. J. P. Muffler, 1973, Resistivity, self-potential, and induced-polarization surveys of a vapor-dominated geothermal system: Geophysics, 38, 1130 1144, doi: 10.1190/1.1440400.

Biographies and photographs of the authors are not available. 